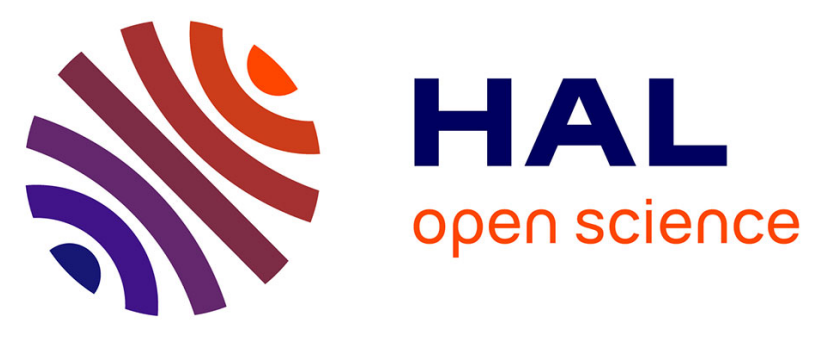

\title{
Multiscale morphological characterization of process induced heterogeneities in blended positive electrodes for lithium-ion batteries
}

\author{
A. Etiemble, N. Besnard, A. Bonnin, Jérôme Adrien, Thierry Douillard, P. \\ Tran-Van, L. Gautier, J.-C. Badot, E. Maire, B. Lestriez
}

\section{To cite this version:}

A. Etiemble, N. Besnard, A. Bonnin, Jérôme Adrien, Thierry Douillard, et al.. Multiscale morphological characterization of process induced heterogeneities in blended positive electrodes for lithium-ion batteries. Journal of Materials Science, 2017, 52 (7), pp.3576-3596. 10.1007/s10853-016-0374-x . hal-03538463

\section{HAL Id: hal-03538463 \\ https://hal.science/hal-03538463}

Submitted on 21 Jan 2022

HAL is a multi-disciplinary open access archive for the deposit and dissemination of scientific research documents, whether they are published or not. The documents may come from teaching and research institutions in France or abroad, or from public or private research centers.
L'archive ouverte pluridisciplinaire HAL, est destinée au dépôt et à la diffusion de documents scientifiques de niveau recherche, publiés ou non, émanant des établissements d'enseignement et de recherche français ou étrangers, des laboratoires publics ou privés. 


\title{
Multiscale morphological characterization of process induced heterogeneities in
}

\section{blended positive electrodes for lithium-ion batteries}

\author{
A. Etiemble ${ }^{\mathrm{a},{ }^{*}}$, N. Besnard ${ }^{\mathrm{b}, \mathrm{c}}$, A. Bonnin ${ }^{\mathrm{d}}$, J. Adrien ${ }^{\mathrm{a}}$, T. Douillard ${ }^{\mathrm{a}}$, P. Tran-Van ${ }^{\mathrm{c}}$, \\ L.Gautier ${ }^{\mathrm{e}}$, J.-C. Badot ${ }^{\mathrm{f}}$ E. Maire ${ }^{\mathrm{a}}$, B. Lestriez \\ a Univ de Lyon, INSA-Lyon, MATEIS UMR CNRS 5510, 7 avenue Jean Capelle, 69621 \\ Villeurbanne Cedex, France \\ ${ }^{b}$ Institut des Matériaux Jean Rouxel (IMN), UMR CNRS 6502, Université de Nantes, \\ 44322, Nantes Cedex 3, France. \\ ${ }^{c}$ Renault Technocentre, DEA-IR, 78084 Guyancourt, France \\ ${ }^{d}$ Swiss Light Source, Paul Scherrer Institut, 5232 Villigen, Switzerland. \\ ${ }^{e}$ Umicore Rechargeable Battery Materials, 1000 Brussels, Belgium. \\ ${ }^{f}$ Institut de Recherche de Chimie Paris, CNRS, Chimie ParisTech, 11 rue Pierre et Marie \\ Curie, 75005, Paris, France
}

Corresponding authors at:

* Univ Lyon, INSA-Lyon, MATEIS CNRS UMR5510, F-69621 Villeurbanne, France Tel.: +33 4724372 47. E-mail addresses: aurelien.etiemble @insa-lyon.fr 


\begin{abstract}
The 3D morphology of $\mathrm{LiNi}_{1 / 3} \mathrm{Mn}_{1 / 3} \mathrm{Co}_{1 / 3} \mathrm{O}_{2}$ (NMC), $\mathrm{LiFePO}_{4}$ (LFP) and blended NMC/LFP electrodes envisioned for electric vehicles Li-ion batteries is characterized by both synchrotron X-ray tomography and FIB/SEM tomography. The size distribution of the active materials, the carbon phase and the pores, the specific surface area of the different solid phases, the concentration variations of the various phases through the total electrode thickness (X-ray tomography) or in smaller volumes (FIB/SEM tomography) are quantified. Results are assessed in relationship with the electrode composition and with their typical slurry rheological properties. Several heterogeneities are evidenced as the fingerprint of phenomena associated with the different processing steps of the electrodes.
\end{abstract}

Keywords: lithium ion batteries; microstructure; X-ray tomography; FIB/SEM tomography; morphological heterogeneity 


\section{Introduction}

Li-ion batteries have adequate performance for most portable electronic devices but cost-effective, high energy and power density devices are needed for new applications such electric vehicles. This way, more efficient and economical electrode processing and increase of the electrode thickness remains critically required to achieve the needs for electric vehicles [1]. Slot-die coating process is commonly used for manufacturing Li-ion battery electrodes. Slurries of active material and conductive additive particles, as well dissolved or dispersed polymer binder are coated on a copper (anode) or aluminum (cathode) current collector substrate. After drying, electrodes are usually compressed (calendered) down to about 20-40\% porosity by passing them through a rolling machine. The electrochemical performance of the resulting electrode is notably dependent on the processing steps that significantly influence its morphology, which may contains defects and heterogeneities. [2-16]. Indeed, the electrode composition, structure and morphology plays a major rule on their electrochemical behavior [17-22].

Several phenomena are at the origin of defects or inhomogeneities. Phase segregation or particles flocculation is usually a consequence of insufficient mixing of the electrode slurry or of strong attractive interparticle forces that destabilize the electrode slurry [4-12]. A gradient composition can also be observed, with generally the heaviest active particles observed near the current collector and the lighter materials such as conductive carbon and binder additives observed at the top of the electrode, as a consequence of settling and/or solvent migration phenomena occurring at the beginning of the drying step in slurries with non-optimized rheological properties and/or active mass loading [13-16]. 
The calendering treatment is essential for obtaining simultaneously high energy, high rate and good cycling stability. Pressing the electrode enhances the electronic wiring of the active mass by improving the contacts between the particles within the electrode and the contact at the interface between the electrode and the current collector, which all have a favorable effect on the electrons distribution and collection [23-30]. However, calendering can degrade the ionic wiring of the active mass due to decreased porosity and increased tortuosity because of particles orientation, or squeezing of the binder phase over the surface of the active mass, which all detrimentally modify the diffusion and insertion/de-insertion of lithium salt species. Moreover, excessive calendering can also cause particles break-up. The optimal performance is thus achieved for an optimal calendering pressure that depends on various factors including the electrode composition, the active material hardness and particle shape, the binder mechanical properties and the type of battery (energy or power) that the electrode is targeted for.

The 3D morphology of various cathode materials for Li-ion batteries has recently been intensively characterized by focused ion beam/scanning electron microscopy (FIB/SEM) and X-ray computed tomography (XRCT). FIB/SEM tomography is destructive but has the ability to provide three-dimensional images at high spatial resolution (typically, a few tens of $\mathrm{nm}$ ) [31]. XRCT is nondestructive and synchrotron sources nowadays allow reaching a nanometer resolution [31-33]. 3D morphologies of $\mathrm{LiCoO}_{2}(\mathrm{LCO})$ and $\mathrm{LCO} / \mathrm{NMC}\left(\mathrm{LiNi}_{1 / 3} \mathrm{Mn}_{1 / 3} \mathrm{Co}_{1 / 3} \mathrm{O}_{2}\right)$ cathodes were first reconstructed and quantified using both FIB/SEM [34-37] and X-ray tomography [37-40]. Zernike phase contrast was furthermore used to visualize the distribution of the carbon phase (conductive agent and binder) [40]. On the other hand, Zielke and al. [41] have input a carbon binder 
modeling in 3D reconstruction of LCO electrode based on X-ray tomography and investigated the influence of its morphology on the conductivity, tortuosity and active surface. This initial work has then been completed by a study incorporating multiple scales and information from X-ray tomography and FIB/SEM imaging combined with the statistical modeling [42]. The microstructure of NMC-based cathodes has previously been studied by synchrotron X-ray radiography and the influence of the weight percent of carbon black $(\mathrm{CB}) /$ binder and the calendering pressure were investigated [43]. The morphology evolution upon cycling of Li-rich NMC electrode has been studied by ex-situ FIB/SEM analysis [44]. Channagiri et al. [45] have investigated LFP-based $\left(\mathrm{LiFePO}_{4}\right)$ cathodes and measured indirectly the porosity, despite the typical pore size much smaller than the resolution. On the other hand, LFP electrode microstructure has been characterized by FIB/SEM tomography $[46,47]$ and synchrotron X-ray tomography at high resolution $(20-50 \mathrm{~nm})[48,49]$. The morphological parameters of LFP and the porosity have been determined and the influence of the compaction has been investigated [49]. Heterogeneities and defects in the electrodes morphology, nevertheless, have rarely been tackled by XRCT and FIB/SEM tomography techniques, which however may provide new sets of information to analyze the influence of the fabrication process.

In this paper, the 3D morphology of NMC, LFP and blended NMC/LFP electrodes envisioned for electric vehicles Li-ion batteries is characterized by both synchrotron X-ray tomography and FIB/SEM tomography. The principal focus of this work, from the battery application point of view, is to study the morphology of electrodes containing a blend of active materials, their particle size and density being different. As illustrated by the literature cited above, the electrochemical performance of an electrode is significantly 
affected by its morphology, which is critically dependent on the processing steps that are themselves dependent on the electrode slurry composition and thus on the active particles textural and colloidal properties. In the case at hand, it is well established that the rheological properties of NMC- and LFP-based electrode slurries are markedly different, which results in significant composition differences of the slurry when these active materials are processed alone with the non-electroactive additives. Indeed, as a consequence of the establishment of numerous polyvinylidene fluoride (PVdF) bridges between the LFP and/or carbon black (CB) nanoparticles, LFP-based slurries show a marked shear thinning behavior and a stronger elasticity than NMC-based ones with the formation of a gel at rest [50]. As a consequence, LFP-based slurries must be richer in solvent than NMC ones to avoid mixing inhomogeneities for example. On another hand, NMC slurries that are too rich in solvent are prone to settling. Finally, it is also known that the electrochemical performance of blended electrodes can be significantly influenced by the spatial organization of the two active materials because they work (charge/discharge) at different potentials [51, 52]. Therefore, spatial variations (heterogeneities) in the distribution of both active materials in blended electrodes are likely to be observed. These ones are finely characterized here, assessed in relationship with composition and discussed with respect to typical slurry rheological properties.

\section{Materials and Methods}

\subsection{Electrode preparation}

Several samples with different compositions have been produced for the present study. Electrodes with typical surface capacity of $2.5 \mathrm{mAh} \mathrm{cm}^{-2}$ were produced on an industrial pilot line (several kg of slurry per electrode batch). Their porosities have been tailored by 
using a roll press. Some samples have been supercalendered using a bench-top hydraulic press in the lab. Table 1 summarizes composition and calculated porosity of all the studied electrodes, which include NMC (samples (A-D)), LFP (samples (J-K) and blended NMC/LFP electrodes (samples (D-I)). The porosity derives from the electrode weight, thickness (measured with a micrometer) and materials density. These electrodes were prepared with a $\mathrm{LiNi}_{1 / 3} \mathrm{Mn}_{1 / 3} \mathrm{Co}_{1 / 3} \mathrm{O}_{2}$ (NMC) compound and/or a $\mathrm{LiFePO}_{4}$ (LFP) one, both supplied by UMICORE. The NMC is a micrometric material in the form of dense spherical particles whose size ranges from 5 to $17 \mu \mathrm{m}\left(\mathrm{D}_{10}=5.6 \mu \mathrm{m}, \mathrm{D}_{50}=9.7 \mu \mathrm{m}, \mathrm{D}_{90}=16.7 \mu \mathrm{m}\right)$. The LFP is a nanometric material that is more or less agglomerated, with a particles/agglomerates sizes range from 0.5 to $10 \mu \mathrm{m}\left(\mathrm{D}_{50}=2.4 \mu \mathrm{m}\right)$, and coated with a few nanometers thick carbon layer. The measured BET specific surfaces are 0.28 and 18.3 $\mathrm{m}^{2} \mathrm{~g}^{-1}$ for NMC and LFP, respectively. Carbon black (CB, BET specific surface of $65 \mathrm{~m}^{2}$ $\mathrm{g}^{-1}$ ) was used as conductive additive, polyvinylidene difluoride (PVdF) as binder and aluminum foil as substrate.

\subsection{SEM observations}

The electrodes were observed in Scanning electron microscopy (SEM) by using a JSM 7600 (JEOL Ltd, Tokyo, Japan). A polished cross-section of the 50/50 NMC/LFP (F) electrode was also performed using a Broad Ion Beam (BIB) milling system (Ilion II / model 697, Gatan Inc., Pleasanton, US). In this case, the sample was first cut to about $5 \times$ $5 \mathrm{~mm}$ size and glue to a shield plate with silver dag (Agar silver paint G3691). With such a device, the final cross-section is comparable to a Focus Ion Beam (FIB) cross-section, but it is wider (roughly 500-1000 $\mu \mathrm{m}$ ). Moreover, the ion guns operated with argon ionizing gas. The accelerating voltage was set to $6 \mathrm{kV}$ and the sputter time was 2 hours. This sample 
was analyzed in SEM with a Supra 55VP (Carl Zeiss Microscopy GmbH, Oberkochen, Germany).

\subsection{BET surface measurements}

A Micrometrics TriStar II 3020 was used to obtain adsorption isotherms of the electrodes mixtures. Measurements were performed at $77 \mathrm{~K}$ under nitrogen, after two hours degassing.

\subsection{Synchrotron X-ray tomography}

X-ray tomography was performed at the TOMCAT beamline of the Swiss Light Source at the Paul Scherrer Institute in Villigen, Switzerland. The electrodes were scanned with a monochromatic X-ray beam at an X-ray energy of $20 \mathrm{keV}$. X-rays were converted in visible light through a Tb:LSO $5.9 \mu \mathrm{m}$ thick scintillator and detected by a CMOS camera (PCO Edge 5.5) scintillator screen at a distance of $10 \mathrm{~mm}$ from the sample. The projection images were magnified 40 times, resulting in voxels with a side length of $0.16 \mu \mathrm{m}$. The exposure time was $600 \mathrm{~ms}$ for each projection and 1001 projections were acquired over a sample rotation of $180^{\circ}$.

The X-ray imaging projections were acquired at a single sample/detector distance $(30 \mathrm{~mm})$ so a phase component is present in the images. The reconstruction of both attenuation and phase (Paganin) was then possible. The contrast observed in the attenuation mode is explained by the Beer-Lambert law. The attenuation coefficient of the BeerLambert law, which is represented in the X-ray radiograph in this mode, is proportional for our energy range to the fourth power of the atomic number $\left(Z^{4}\right)$ and the density $(\rho)$ of the investigated material [53]. The phase contrast mode is especially useful as a way of increasing the contrast between objects that attenuate the beam similarly [54]. The 
propagation phase contrast, used in this paper, exploits the Fresnel diffraction of $\mathrm{X}$-rays [32]. Using the single-distance phase retrieval approach developed by Paganin, the resulting images have enhanced edge contrast which allows easier processing and segmenting.

For the quantitative analysis, the tomographic reconstructions were rescaled, resulting in a voxel length of $0.32 \mu \mathrm{m}$, and cropped to obtain a volume of $128 \mu \mathrm{m} * 160$ $\mu \mathrm{m} *$ thickness.

\subsection{FIB/SEM tomography}

FIB/SEM tomography was performed for four of the samples: NMC (sample (A)), as-received blended NMC/LFP (sample (F)), supercalendered blended NMC/LFP (sample (H)) and LFP (sample (J) electrodes). Serial FIB/SEM imaging was performed using a FIB/SEM workstation (NVision 40; Carl Zeiss Microscopy GmbH, Oberkochen, Germany) combining a SIINT zeta FIB column (Seiko Instruments Inc. NanoTechnology, Japan) with a Gemini I SEM column. The NVision 40 platform is also equipped with a multi-nozzle SIINT gas injection system (GIS). The angle between the FIB and SEM columns was $54^{\circ}$. All NMC and blended NMC/LFP electrodes were preliminarily polished with the focus ions beam to decrease the surface irregularity. A carbon layer $(25 \times 25 \times 1$ $\mu \mathrm{m}^{3}$ ) was then deposited on the top of the sample by in situ ion beam induced deposition (IBID) to protect the surface during slicing in order to achieve sharp upper edges and minimize curtaining artifacts. Three reference lines were imprinted into the carbon layer for post alignment of the image stack. SEM imaging was done in both secondary electrons (SE) and backscattered electron (BSE) modes with an accelerating voltage of $1.5 \mathrm{keV}$. Prior to serial sectioning, a trench was milled to a depth that freed up a sufficient cross- 
sectional surface. This step was performed with a coarse ion beam current of $27 \mathrm{nA}$ with an accelerating voltage of $30 \mathrm{keV}$. Then, serial FIB sectioning was done with a current of $3 \mathrm{nA}$ at $30 \mathrm{keV}$ and an increment step of $10 \mathrm{~nm}$ (z-spacing). 3D reconstruction of the composite electrode was performed with a voxel size of $10 \times 10 \times 10 \mathrm{~nm}^{3}$ from stacks corresponding to a volume of $441 \mu \mathrm{m}^{3}(10.0 \times 9.0 \times 4.9 \mu \mathrm{m})$ for (A), $284 \mu \mathrm{m}^{3}(10.0 * 4.0 * 7.1$ $\mu \mathrm{m})$ for $(\mathrm{F}), 327 \mu \mathrm{m}^{3}(10.1 \times 6.0 \times 5.4 \mu \mathrm{m})$ for $(\mathrm{H})$ and $440 \mu \mathrm{m}^{3}(10.0 \times 8.0 \times 5.5 \mu \mathrm{m})$ for $(\mathrm{J})$.

After acquisition, the image processing and analysis were performed with the Fiji free software [55]. In a first step, the images were aligned based on the reference lines to correct small $x-y$ drifts. The image contrast was then adjusted to correct its evolution upon ablation ( $z$ direction) and the shade effect ( $y$ direction) associated with the acquisition geometry. Finally, vertical stripes (curtaining effect) on the SEM images, associated with the FIB ablation, were removed using a variational algorithm Fiji plug-in [56].

\section{Results}

\subsection{Electrodes microstructure}

\subsubsection{SEM observations}

Scanning electron microscopy (SEM) was used for preliminary observation of the electrodes and SEM images of the cross-section of various electrodes are shown in Figure 1. The NMC electrode has a well-defined morphology (Figure 1a). The large spherical NMC particles are about $10 \mu \mathrm{m}$ in size and their packing determines micrometric voids (cavities). The PVdF binder and CB conductive carbon additives are coagulated together to form a second phase that is spread throughout the electrode between the NMC particles, gluing them (sample A). When the additives content increases (samples B, C and D) the $\mathrm{CB}+\mathrm{PVdF}$ phase fills the micrometric cavities between the NMC particles and is more 
spread over their surfaces (Figure 1b). In the LFP electrode the packing of the nanometric LFP primary particles, some of them being aggregated in secondary particles of a few micrometers, leaves space for small voids (of size less than about $100 \mathrm{~nm}$ ) and the $\mathrm{CB}+\mathrm{PVdF}$ phase is hardly discernible, as it is diluted within the network of LFP primary and secondary particles (Figure 1f). The blended NMC/LFP electrodes have intermediate morphologies that vary gradually between NMC and LFP ones (Figure 1c-e). Furthermore, voids like microcracks at interfaces between NMC particles and the LFP/CB+PVdF matrix are also evidenced (Figure S1).

These SEM observations are however poorly informative and only qualitative with respect to the morphology of these electrodes. To characterize quantitatively the electrodes microstructure, X-ray and FIB/SEM topographies have thus been performed.

\subsubsection{Tomography analysis}

An electrode X-ray cross-section of each sample is shown for phase contrast in Figure 2 and attenuation contrast in Supplementary Information (Figure S2). Same gray scale ranges were used for all the samples. The left side $(x=0)$ corresponds to the aluminum current collector (Al) and the right side to the electrolyte. A key step of the process to reconstruct and quantify the $3 \mathrm{D}$ structure is the segmentation of the various phases within the electrode (NMC, LFP, CB+PVdF carbon phase and porosity). The NMC spherical particles can be quite easily distinguished as the brightest voxels in the phase

contrast image (Figure 2). The intensity at the minimum between the two characteristic peaks of the grey scale histograms (not shown) is selected as threshold to segment the NMC particles and the other phases (LFP, carbon phase and porosity). The resolution used for obtaining the images above is one of the best achievable using parallel beam synchrotron 
$\mathrm{X}$-Rays to date. Note that this resolution is not good enough to provide a satisfying image of the smallest constituents of our electrodes i.e. porosity and LFP. FIB/SEM is then mandatory to analyze the structure at this smallest scale.

It is not straightforward to segment the SEM images obtained by FIB/SEM tomography due to the presence of the pores, as shown in Figure 3. This is due to the socalled "shine through artifacts" (i.e. in SEM image, the solid phase located below the observed plane is visible through the porosity). This prevents efficient image segmentation based on the classic grey value threshold. Thus, a Fiji software macro has been developed, based on the segmentation method described in ref. [57], and implemented in order to precisely identify the pores and the solid phase. The resulting segmentation outline of the pores, shown in red in some of the typical SEM images (Figure 3), demonstrates the efficiency of this method. Active materials (NMC and LFP) and $\mathrm{CB}+\mathrm{PVdF}$ carbon phase were clearly identified by thresholding of BSE grey level images. Finally, NMC and LFP particles were distinguished by both thresholding of BSE images grey level and manual image proceeding. Note however that the size of the NMC particles is very large and only one or two particles are present in each FIB/SEM tomography, hence the interest of the preceding X-Ray images.

3D multiscale quantitative analyses could be performed thanks to efficient segmentation of X-ray and FIB/SEM tomography reconstructions. X-ray tomography reconstructions of NMC particles are shown in Figure 4a-d for various electrode compositions. The FIB/SEM tomograph reconstructions of the active material, the $\mathrm{CB}+\mathrm{PVdF}$ phase and porosity are shown in Figure 4 for NMC (e-g), as-received NMC/LFP 50/50 (h-j), supercalendered NMC/LFP 50/50 (k-m) and LFP electrodes (n-p). 
The samples composition and morphological parameters extracted from these analyses are summarized in Table 1-4.

\subsection{Material size distribution}

The particle size distribution can be measured using sequential opening operations. This process consists in a combination, with successive structural elements of size (n), of image erosion followed by dilation. The difference between the dilated and the initial image allows retrieving the fraction of elements of thickness $2 n$ in the image [58]. Another particle size characterization consists in the identification of each particle using the cell segmentation (watershed) of a 3D morphological free software (iMorph) [59]. This allows us to label differently each particle, even if they are connected, and hence to quantify their volume. Surface and volume were determined using marching cube algorithms [60]. The particle size distributions for NMC, LFP and PVdF+CB particles are shown in Figure 5. 3D views of the NMC and LFP particles size distribution (sample F) are shown in Supplementary Information (Figure S3). The cumulative distribution of NMC particles volume for all the compositions is also superimposed in Supplementary Information (Figure S4).

NMC particles exhibit spherical shape with typical sizes from $\sim 1 \mu \mathrm{m}$ to $\sim 20 \mu \mathrm{m}$ (Figure 5a, X-Ray tomography). The NMC particle size distribution is similar whatever the sample, which is in accordance with the identical source of powder used for the electrode preparation. The median particle size $\left(D_{50}\right)$ is estimated by this image processing at around $7 \mu \mathrm{m}$. The LFP particle size distribution (Figure 5b, FIB/SEM tomography) varies from few ten nanometers to around 800nm. The LFP particle size distribution for the as received NMC/LFP $(\mathrm{F})$ and LFP $(\mathrm{J})$ are also similar. All this confirms that processing 
doesn't change the size distribution of the active particles except for super-calendering (electrode $\mathrm{H}$ ) for which the LFP particle size is smaller. This could be explained by the fragmentation of LFP secondary particles during the bench-top hydraulic pressing.

The comparison of NMC (A) and NMC/LFP (H) electrodes, having both same $\mathrm{CB}+\mathrm{PVdF}$ mixture amount (in \%wt, see Table 1), shows that the $\mathrm{CB}+\mathrm{PVdF}$ phase (Figure 5c, FIB/SEM tomography) is much more finely distributed (clusters smaller than 200nm) in NMC/LFP electrode as a consequence of the presence of LFP nanoparticles that play the role of a dilution media. In NMC (A) electrode, the $\mathrm{CB}+\mathrm{PVdF}$ phase is in the form of larger clusters up to $1 \mu \mathrm{m}$. The comparison of NMC/LFP (H) and LFP (J) electrode, having both same $\mathrm{CB}+\mathrm{PVdF}$ mixture amount (in wt \%), shows that in LFP electrode there is nearly $20 \%$ of the $\mathrm{CB}+\mathrm{PVdF}$ phase that is in the form of clusters larger than $200 \mathrm{~nm}$ (see also Figure 4o). This result suggests that the PVdF content was too low in this electrode to achieve a good distribution of the CB particles. Finally, for the NMC/LFP electrode, although there is more $\mathrm{CB}+\mathrm{PVdF}$ mixture in $(\mathrm{F})$ than in $(\mathrm{H})$, this phase is similarly finely well distributed in the two electrodes.

The specific surface area values measured for the different materials and for the different electrodes are compared in Table 3 and Table 4, respectively. The theoretical value is determined from the BET surface area of the pristine powders and their weight fraction in the electrode composition. For LFP, two theoretical values are given, as the carbon coating significantly contributes to the powder BET surface area that is thus more than two times higher than the value calculated from mean particle size. For electrode, the one labeled "BET" is measured by the BET technique, and the one labeled "FIB/SEM" is measured by image analysis of FIB/SEM tomography reconstructions. FIB/SEM specific 
surface area of the electrodes is calculated using a marching cube algorithm on the open pores, while FIB/SEM specific surface area of NMC, LFP and CB+PVdF is calculated separately for each phase after segmentation. The resulting surface area (in $\mu \mathrm{m}^{2} . \mu \mathrm{m}^{-3}$ material) is divided by the average density, estimated from volume contribution of each phase in the studied reconstruction, for the electrode specific surface area and divided by the material density for NMC, LFP and CB+PVdF specific surface area. FIB/SEM shows that the specific surface area of the NMC particles is close to expected value (Table 3), except for $(\mathrm{H})$, where a higher value may reflects the cracking of the active particles by supercalendering. The specific surface area of the LFP particles is about 1.5 to 2 times lower than the value expected based on the size of the LFP particles, which reflects some agglomeration of LFP particles. The experimental BET specific surface is a factor of 2.35 (A) to $1.25(\mathrm{~J})$ lower than the theoretical value based on the pristine powder BET surface areas (Table 4). For the NMC (A) electrode, FIB/SEM image analysis reveals that the large difference between the theoretical and measured values is due to the significant $\mathrm{CB}$ agglomeration into large $\mathrm{CB}+\mathrm{PVdF}$ clusters (Table 3). Indeed, the specific surface area developed by these $\mathrm{CB}+\mathrm{PVdF}$ clusters is only $3 \mathrm{~m}^{2} \mathrm{~g}^{-1}$, which is to be compared to the BET surface area of the CB powder $\left(65 \mathrm{~m}^{2} \mathrm{~g}^{-1}\right)$. Taking into account the specific surface area measured by FIB/SEM and the weight contribution in the electrode composition of NMC and $\mathrm{CB}+\mathrm{PVdF}$, the respective contribution of these two phases to the specific surface area of the electrode mixture $\left(0.44 \mathrm{~m}^{2} \mathrm{~g}^{-1}\right)$ is calculated to be $42 \%$ for NMC and $58 \%$ for $\mathrm{CB}+\mathrm{PVdF}$. For the LFP $(\mathrm{J})$ electrode there is little difference between the theoretical and measured values if one considers a value of $8 \mathrm{~m}^{2} \mathrm{~g}^{-1}$ for the pristine powder. Such an assumption is justified because the PVdF binder likely adsorb at the surface of the particles 
closing the carbon coating microporosity. Both the $\mathrm{CB}$ and the LFP particles are agglomerated to some extent. $\mathrm{CB}$ is however significantly less agglomerated with PVdF than in NMC (A) electrode. Indeed, in ( $\mathrm{J})$ the specific surface area developed by these $\mathrm{CB}+\mathrm{PVdF}$ masses is $20 \mathrm{~m}^{2} \mathrm{~g}^{-1}$ (Table 3), which represents about $26 \%$ of the specific surface area of the electrode mixture. The LFP particles show a specific surface of $4.4 \mathrm{~m}^{2}$ $\mathrm{g}^{-1}$, which is around 2 times less than the LFP powder specific surface calculated from the particles diameter $\left(8 \mathrm{~m}^{2} \mathrm{~g}^{-1}\right)$ and represents about $74 \%$ of the specific surface area of the electrode mixture. The NMC/LFP blended electrodes $(\mathrm{F})$ and $(\mathrm{H})$ show intermediate BET surface areas between the two reference electrodes, which is obviously due to the $50 / 50$ weight ratio of two active materials. The respective contribution of the different phases to the specific surface area of the electrode mixture $\left(3.52\right.$ and $4.79 \mathrm{~m}^{2} . \mathrm{g}^{-1}$ for $\mathrm{F}$ and $\mathrm{H}$, respectively) is calculated to be $3 \%$ and $3 \%$ for NMC, $59 \%$ and $69 \%$ for LFP, and $38 \%$ and $28 \%$ for $\mathrm{CB}+\mathrm{PVdF}$, in $\mathrm{F}$ and $\mathrm{H}$, respectively.

\subsection{Material concentration distribution}

To characterize the volumetric spatial distribution inside the electrode, the NMC density, estimated by X-ray tomography, has been calculated in slices perpendicular to the thickness direction (x) and then plotted as density value profiles along this axis. Attenuation mode may provide information on the densities, due to the theoretical proportionality of the voxel value with the average attenuation coefficient. This characteristic can be affected by the phase contrast phenomenon, which enhances the contrast of the surfaces even in the attenuation mode. The use of monochromatic X-ray in synchrotron beamline however allows correlating, in a first approximation, the average grey values and the theoretical LFP volume density. We use the fact that the carbon phase 
of the electrodes (CB and PVdF) exhibits negligible attenuation, comparably close to the porosity one (same grey value) [53]. Also, average grey value as a function of the theoretical LFP density for blended NMC/LFP and all LFP electrodes shows that the Beer Lambert law is rather well respected as a linear evolution is observed (Supplementary Information, Figure S5b). The grey value of the LFP-PVdF-CB-porosity phase has been averaged in slices perpendicular to the thickness direction (x) (Figure S5a) and then plotted as LFP density value profiles along this axis, based on the linear correlation described above (Figure S5c). For all the compositions and compactions, the identical LFP volume density $(\sim 45 \%)$ at null thickness is an artifact associated with the aluminum current collector, which cannot be segmented. The profiles at low thickness are also affected by the aluminum surface irregularity. In addition, an abrupt peak of LFP density is observed at the surface for all the composition. This can be related to the phase contrast, which is particularly pronounced between inside and outside the electrode.

NMC profiles through the electrode thickness are shown in Figure 6a and $6 \mathbf{b}$ for NMC and blended NMC/LFP electrodes, respectively. LFP profiles are shown in Figure 6c and $\mathbf{6 d}$ for LFP and blended NMC/LFP electrodes, respectively. The average NMC and LFP density, the relative standard deviations (RSD) and the density profiles slopes in the electrode bulk are summarized in Table 1. The average NMC densities, estimated by Xray tomography, are close to the ones calculated from the electrode weight, thickness and material density but however appear slightly lower for all the compositions. It could be associated with some inaccuracy in the estimation of the density due to the irregular thickness of the deposit. The NMC density fraction of the $25 \%$ least and most voluminous NMC particles has been calculated in slices perpendicular to the thickness direction (x) and 
then plotted as density fraction value profiles along this axis for all NMC (Figure 6e-f) and blended NMC/LFP electrodes (Figure 6g-h).

In order to characterize precisely the LFP and PVdF+CB carbon phase density distribution, FIB/SEM tomography analysis was performed. The NMC, LFP, PVdF+CB carbon phase density and the porosity have been calculated in slices perpendicular to the depth direction (y) and then plotted as density value profiles along this axis. The top side $(y=0)$ of the studied volume corresponds to the surface closest to the electrode surface. The profiles for all NMC, as-received blended NMC/LFP, supercalendered blended NMC/LFP and all LFP electrodes are shown in Figure 7. The average densities and porosity with the relative standard deviation are summarized in Table 2.

The average density estimated by FIB/SEM tomography is affected by the NMC particles due to their large size compared to the studied volume. The LFP density/porosity and LFP density/PVdF+CB density ratio, given in Table 2, was therefore used to evaluate the electrode homogeneity.

\subsubsection{Current collector/electrode interfaces}

For all the compositions and compactions, the NMC density (Figure 6 a-b) is very low near the current collector and increases quickly over a thickness of $\sim 10 \mu \mathrm{m}$. In addition, the NMC density fraction of the smallest particles (Figure $6 \mathbf{e}$ and $\mathbf{6 g}$ ) is high near the current collector and then decreases, while the NMC density of the biggest particles (Figure 6f and 6h) is low near the current collector and then increases. These profiles reflect an accumulation of smaller particles at the current collector surface as well as a low contact surface area between the current collector and the first layer of NMC particles, due to their spherical shape and micrometric size. This observation is illustrated on the 
tomogram at a thickness of $4 \mu \mathrm{m}$ for the sample (C) (Figure S6a). In complement, SEM investigations show that the NMC (A) to (D) electrodes have a CB+PVdF layer accumulated near the current collector (Figure S7a and S7b). No information could be obtained for the LFP density near the current collector (see experimental section). However, it is likely that a same phenomenon could occur, with an accumulation near the current collector of a layer rich in $\mathrm{LFP} / \mathrm{CB}+\mathrm{PVdF}$ and depleted in NMC.

\subsubsection{Density profiles in NMC electrodes}

For the NMC (B) to (D) electrodes with the higher PVdF and CB contents (Figure 6a), the NMC density in the bulk tends to decrease through the electrode thickness from above the current collector toward the top of the electrode. This evolution is clearly discernible when comparing the X-ray tomograms of (C) at a thickness of $18 \mu \mathrm{m}$ and at $60 \mu \mathrm{m}$ (Figure S6b and c). The slope of NMC density through the electrode thickness, estimated by linear correlation of the density profiles, is summarized in Table 1. For the (B) to (D) electrodes, the relative variation of the volume density of NMC particles through the electrode thickness is $\sim 0.1 \% . \mu \mathrm{m}^{-1}$. In addition, the NMC density fraction of the smallest particles increases (Figure 6e), while the NMC density of the biggest particles decreases (Figure 6f), from the current collector towards the top of the electrode, whatever the PVdF and CB contents. These phenomena are however less severe for (A) that contains less binder and conductive carbon additives. Zooming in the bulk of the electrode by FIB/SEM tomography shows large and opposite variations of $\mathrm{NMC}$ and $\mathrm{CB}+\mathrm{PVdF}$ density in the scanned volume (Figure 7a). The PVdF binder and CB conductive carbon particles are coagulated all together as shown by the low specific surface area displayed by this phase compared to the nanometric size of the CB powder (Table 3). This phase forms micrometer 
thick strands (Figure 5c) that are spread at the surface of NMC particles or between the NMC particles, gluing them, throughout the whole electrode, as shown in the 3D reconstruction (Figure 4f) and SEM images (Figure 1a-b).

\subsubsection{Density profiles in LFP electrodes}

For LFP (J) electrode, the LFP volume density (Figure 6c) is constant in the bulk with low relative standard derivation $(\mathrm{RSD}<2 \%)$. At a smaller scale and within an $8 \mu \mathrm{m}$ thick layer close to the electrode surface (FIB/SEM tomography was done in a volume at the surface of the electrode), subtle and smooth density variations of the LFP and $\mathrm{CB}+\mathrm{PVdF}$ phases are observed (Figure 7d). Table 2 gives the LFP/porosity and the $\mathrm{LFP} / \mathrm{CB}+\mathrm{PVdF}$ mixture ratio, estimated by FIB/SEM tomography and calculated from the electrode composition, materials density, the electrode weight and thickness. Moreover, Table 1 and Table 2 allow us to compare the LFP volume density averaged over the whole electrode (Table 1, X-Ray tomography) and at the electrode surface (Table 2, FIB/SEM tomography), which values are 52.6 and $58.5 \%$, respectively. The higher LFP volume density and higher LFP/porosity ratio at the electrode surface reflect the higher densification induced by the roll pressing step compared to what it is in the bulk of the electrode. The slightly different $\mathrm{LFP} / \mathrm{CB}+\mathrm{PVdF}$ ratio at the electrode surface and in the electrode bulk (6.7 and 5.9, respectively) reflects some spatial variations in the electrode slurry composition.

\subsubsection{Density profiles in NMC/LFP blended electrodes}

With respect to the NMC/LFP blends, the situation seems similar to the NMC electrodes for the 75/25 composition (E). From the bottom to the top of the electrode, the NMC density clearly decreases (Figure 6b), while the LFP density increases (Figure 6d). 
Moreover, the NMC density fraction of the smallest particles (Figure $\mathbf{6 g}$ ) increases and the biggest particles (Figure $\mathbf{6 h}$ ) are mostly observed at the bottom part of the electrode. The NMC (Figure 6b) and LFP density (Figure 6d) vary less through the electrode bulk for the 50/50 and 25/75 compositions with a slight decrease of NMC density for the asreceived $(F)$ and $(\mathrm{G})$ electrodes when looking closer to the electrode surface. In addition, the density fraction of the smallest (Figure 6g) and biggest NMC particles (Figure 6h) appear also fairly constant through the electrode thickness. Quantitatively, the relative variation of the volume density of NMC particles through the electrode thickness is only $\sim 0.05 \% . \mu \mathrm{m}^{-1}$ for (F) to (I), compared to more than $\sim 0.10 \% . \mu \mathrm{m}^{-1}$ for (B) to (D). The electrode blends also show stronger local variations in the LFP volume density profiles than for all LFP electrodes (relative standard deviation values in Table 1). This is likely to be associated with the distribution of the micrometric NMC particles that delimit volumes from which LFP particles are excluded. Such local variations in the density profiles from $\mathrm{X}$-Ray tomography are also observable in the density profiles at smaller scale from FIB/SEM tomography (Figure 7b-c). SEM image of FIB polished (F) cross-section (Figure S1) reveals other kinds of morphological heterogeneities at the origin of local variations in the density profiles, such as large agglomerates of LFP particles (typically 10 $\mu \mathrm{m}$ in size) and large cavities in NMC rich-zones. The latter are probably a consequence of the mismatch in the NMC and LFP particles size and hardness. The stacking of the bigger and harder NMC particles can trap voids in their inter spaces, which induce locally higher porosity values. The homogeneity of LFP density, characterized by the relative standard deviation (Table 2), decreases as the NMC density decreases. This reflects the influence of the NMC particle presence in the slurry on the distribution of the LFP cluster 
in the electrode due to the formation of cavities. The increase of conductive agent and binder contents seems to paradoxically increase the LFP volume density heterogeneity (sample (F) vs. (H)).

\subsection{Influence of supercalendering}

Comparison of as-received (B) and (C) and supercalendered (D) NMC electrodes shows that using a bench-top hydraulic press is clearly less efficient than a rolling press for increasing the electrode density. Indeed, supercalendering (C) (to form sample (D)) doesn't show significant change of thickness and density distribution, while roll-pressing allowed reaching a higher density for the same electrode composition (B) (Figure 6a). This could be related to the already high compaction of the NMC particles in the as-received electrodes which prevents sliding when a vertical stress is applied to the active layer with the benchtop. Moreover, observation of the X-ray tomograms taken at the surface of (D) (Figure S6d) reveals that supercalendering induces the cracking of NMC particles at the electrode surface.

As for the all NMC samples, the supercalendering of the 50/50 composition electrode with a bench-top vertical press doesn't modify significantly the electrode thickness. However, it increases the NMC density both at the surface and near the current collector as highlighted by the small arrows on NMC density profiles in Figure $\mathbf{6 b}$. The effect of this treatment, which induces the cracking of NMC particle at the surface, is also illustrated in Figure S6e and S6f. Moreover, FIB/SEM tomography clearly shows that the porosity is lower at the electrode surface in the case of supercalendered (H) (Figure 7c) compared to as-received (F) (Figure 7b). In addition, the LFP density/porosity ratio (Table 2), estimated by FIB/SEM tomography, is close to the one calculated from the electrode 
weight, thickness and material density for the as-received NMC/LFP (F). In comparison, the LFP density/porosity ratio, estimated by X-ray tomography, for the supercalendered $\mathrm{NMC/LFP}(\mathrm{H})$ at its surface is much higher than the expected one, i.e. 3.6 vs. 1.9. This all shows that the bench-top hydraulic pressing induced a densification of the electrode surface, as well as near the current collector in the case of the 50/50 composition. This process also induces the cracking at the electrode surface of NMC particles (Figure S6f) and LFP agglomerates, which leads to an increase of their specific surface area (Table 3). For the LFP electrode, supercalendering $(\mathrm{J})$ to $(\mathrm{K})$ with a bench-top press leads to a decrease of the electrode thickness and to an increase of the LFP volume density (i.e. a decrease in the porosity) homogeneously.

\section{Discussion}

Electrode microstructure is known to be strongly affected by many factors of the Slot-die coating process. In the following discussion we suggest the possible causes at the origin of the heterogeneities detected and quantified by the tomography characterizations.

Near to the current collector, the lower NMC density and the occurrence of an accumulated layer of $\mathrm{CB}+\mathrm{PVdF}$ (or $\mathrm{LFP} / \mathrm{CB}+\mathrm{PVdF}$ ) could result from the migration of the NMC particles during the casting step. Indeed, when a slurry is forced to flow against a solid substrate, the stress field around a particle can interact with the substrate, causing it to migrate inward [61], the larger the particle, the more significant this phenomenon. In general nanometric particles are not affected by migration phenomenon. The density and particles size gradients through the electrode thickness could be associated with the sedimentation of the NMC particles during the slurry casting and drying $[13, \mathbf{1 4}]$, and/or to the migration of the lighter $\mathrm{CB}+\mathrm{PVdF}$ phase with the NMP solvent during drying [15], 
a sharper density gradient being observed for (B) to (D) containing more binder and conductive carbon additives.

LFP electrodes appears highly homogeneous and there is less sedimentation and migration phenomena in the slurries containing blends of NMC and LFP, provided that the LFP fraction is high enough, here at least half of the active mass quantity. This could be related to the nanometric size of the LFP particles that are neither prone to migration during casting nor to settling. Such a result could also be due to a higher viscosity of the LFP-rich slurries as a consequence of the establishment of a physical gel, formed by the LFP and CB nanoparticles bridged by the PVdF polymer chains, able to sustain the weight of the heaviest NMC particles and to prevent their settling $[\mathbf{1 4}, \mathbf{5 0}]$.

\section{Conclusions}

3D morphology of NMC, LFP and blended NMC/LFP electrodes has been characterized by both synchrotron X-ray tomography and FIB/SEM tomography. Several morphological heterogeneities have been detected and quantified for these $2.6 \mathrm{mAh} \mathrm{cm}^{-2}$ electrodes manufactured on an industrial pilot fabrication line (see also scheme in Figure 8):

- In electrodes containing NMC, the layer close to the current collector (thickness up to about $10 \mu \mathrm{m}$ ) is depleted in the biggest NMC particles and is enriched in the smallest NMC and the smaller LFP particles, as well as in the $\mathrm{CB}+\mathrm{PVdF} / \mathrm{phase}$, reflecting a rheological induced segregation phenomenon. This feature likely plays on the electrical contact resistance with the current collector.

- Above this NMC depleted layer, the electrode composition is close to its nominal value but the NMC density and the mean NMC particle size decrease through the electrode 
thickness toward its top surface, reflecting a settling phenomenon. This gradient in NMC density has been quantified between 0.05 and $0.1 \%$ per $\mu \mathrm{m}$. The occurrence of density gradient for electrodes prepared through conventional casting process is a limitation toward the fabrication of very thick electrodes for high energy density batteries. This gradient in NMC density and particle size is however less severe in the LFP-richer blends. The LFP electrode shows no gradient in LFP density through its thickness, a feature associated with the nanometric size of these active particles that are not prone to settling. At the electrode surface a higher LFP density than in the bulk is observed, 58.5 vs. $52.6 \%$ (corresponding porosity of 33.8 vs. $37 \%$ ), respectively, as a consequence of the calendering.

- Furthermore, local morphological heterogeneities, such as large agglomerates of LFP particles (typically $10 \mu \mathrm{m}$ in size) and large cavities in NMC rich-zones, were observed.

- Supercalendering with bench-top hydraulic pressing could induce a densification of the electrode but mostly at its surface and near the current collector for LFP, and for the 50/50 and 25/75 NMC/LFP blended electrodes. However, in the case of the NMC electrode it only resulted in the cracking of NMC particles at the electrode surface.

- The specific surface area of the electrodes has been characterized and the value from image analysis appears in the same order of magnitude as BET measurements. Ratio of theoretical to measured values varies for NMC, NMC/LFP and LFP electrodes. In NMC electrode, ratio equal to 2.35 reflects the significant coagulation of the $\mathrm{CB}$ particles by the PVdF binder into micrometric conductive strands. In LFP electrode, ratio is 1.25 as the CB particles are much less coagulated and more finely dispersed. An intermediate ratio value is found for NMC/LFP electrodes. 
These results demonstrate the efficiency of XRCT and FIB/SEM tomography techniques to analyze the architecture of composite electrodes for Li-ion batteries and evidenced heterogeneities in relationships with the fabrication process. Future work will focus on the electrochemical performance of the same electrodes.

\section{Acknowledgements}

The authors would like to acknowledge IMD (Institut de la Mobilité Durable Sustainable Mobility Institute) and the network METSA (Microscopie Electronique et Sonde Atomique) for financial support. Thanks are also due to the CLYM (Centre Lyonnais de Microscopie: www.clym.fr) supported by the CNRS, the "Grand Lyon" and the Rhône-Alpes Region for use of the Zeiss NVision40 FIB/SEM. This work was made possible by the facilities provided by Swiss Light Sources (Paul Scherrer Institut) and the technical support from the staff of the TOMCAT beamline. This research has also received

funding from the European Community's Seventh Framework Programme under CALIPSO. 


\section{References}

[1] Wood III DL, Li J, Daniel C (2015) Prospects for reducing the processing cost of lithium batteries. J. Power Sources 275: 234-242. doi:

10.1016/j.jpowsour.2014.11.019

[2] Mohanty D, Hockaday E, Li J, Hensley DK, Daniel C, Wood III DL (2016) Effect of electrode manufacturing defects on electrochemical performance of lithium-ion batteries: Cognizance of the battery failure sources. J. Power Sources 312: 70-79. doi: 10.1016/j.jpowsour.2016.02.007

[3] Schmitt M, Baunech M, Wengeler L, Peters K, Junges P, Scharfer P, Schabel W (2013) Slot-die processing of lithium battery electrodes-Coating window characterization. Chem. Eng. Process. 68: 32-37. doi: 10.1016/j.cep.2012.10.011

[4] Ligneel E, Lestriez B, Hudhomme A, Guyomard D (2007) On the origin of the pre-plasticizer effect of the composite electrode for lithium batteries. Electrochem. Solid-State Lett. 10: A122-A126. doi: 10.1149/1.2437660

[5] Lee GW, Ryu JH, Han W, Ahn KH, Oh SM (2010) Effect of the slurry preparation process on electrochemical performances of $\mathrm{LiCoO}_{2}$ composite electrode. J. Power Sources 195: 6049-6054. doi: 10.1016/j.jpowsour.2009.12.101

[6] Porcher W, Lestriez B, Jouanneau S, Guyomard D (2010) Optimizing the surfactant for the aqueous processing of $\mathrm{LiFePO}_{4}$ composite electrodes. J. Power Sources 195: 2835-2843. doi: 10.1016/j.jpowsour.2009.11.088

[7] Zhu M, Park J, Sastry AM (2011) Particle interaction and aggregation in cathode material of Li-ion batteries: a numerical study. J. Electrochem. Soc. 158: A1155A1159. doi: 10.1149/1.3625286 
[8] Cornut R, Lepage D, Schougaard SB (2012) Ohmic drop in $\mathrm{LiFePO}_{4}$ based lithium battery cathodes containing agglomerates. J. Electrochem. Soc. 159: A822-A827. doi: 10.1149/2.081206jes

[9] Li J, Armstrong BL, Daniel C, Kiggans J, Wood III DL (2013) Optimization of multicomponent aqueous suspensions of lithium iron phosphate $\left(\mathrm{LiFePO}_{4}\right)$ nanoparticles and carbon black for lithium-ion battery cathodes. J. Colloid Interface Sci. 405: 118-124. doi: 10.1016/j.jcis.2013.05.030

[10] Li CC, Lin YS (2012) Interactions between organic additives and active powders in water-based lithium iron phosphate electrode slurries. J. Power Sources 220: 413-421. doi: 10.1016/j.jpowsour.2012.07.125

[11] Nguyen BPN, Chazelle S, Cerbelaud M, Porcher W, Lestriez B (2014) Manufacturing of industry-relevant silicon negative composite electrodes for lithium ion-cells. J. Power Sources 262: 112-122. doi:

10.1016/j.jpowsour.2014.03.119

[12] Cerbelaud M, Lestriez B, Videcoq A, Ferrando R, Guyomard D (2015) Understanding the structure of electrodes in Li-ion batteries: a numerical study. J. Electrochem. Soc. 162: A1485-A1492. doi: 10.1149/2.0431508jes

[13] Ligneel E, Lestriez B, Hudhomme A, Guyomard D (2007) Effects of the solvent concentration (solid loading) on the processing and properties of the composite electrode. J. Electrochem. Soc. 154: A235-A241. doi: 10.1149/1.2431316

[14] Porcher W, Lestriez B, Jouanneau S, Guyomard D (2009) Design of aqueous processed thick $\mathrm{LiFePO}_{4}$ composite electrodes for high-energy lithium battery. J. Electrochem. Soc. 156: A133-A144. doi: 10.1149/1.3046129 
[15] Li CC, Wang YW (2011) Binder distributions in water-based and organic-based $\mathrm{LiCoO}_{2}$ electrode sheets and their effects on cell performance. J. Electrochem. Soc. 158: A1361-A1370. doi: 10.1149/2.107112jes

[16] Lim S, Ahn KH, Yamamura M (2013) Latex migration in battery slurries during drying. Langmuir 29: 8233-8244. doi: 10.1021/la4013685

[17] Chang Y-C, Peng C-T, Hung I-M (2014) Effects of particle size and carbon coating on electrochemical properties of $\mathrm{LiFePO}_{4} / \mathrm{C}$ prepared by hydrothermal method. J. Mater. Sci. 49:6907-6916. doi: 10.1007/s10853-014-8395-9

[18] Yang X, Li, C, Zhang G, Yang C (2015) Polystyrene-derived carbon with hierarchical macro-meso-microporous structure for high-rate lithium-ion batteries application. J. Mater. Sci. 50:6649-6655. doi: 10.1007/s10853-0159214-7

[19] Xia L; Qiu K, Gao Y, He X, Zhou F (2015) High potential performance of Cerium-doped $\mathrm{LiNi}_{0.5} \mathrm{Co}_{0.2} \mathrm{Mn}_{0.3} \mathrm{O}_{2}$ cathode material for Li-ion battery. J. Mater. Sci. 50:2914-2920. doi: 10.1007/s10853-015-8856-9

[20] Khalil A, Lalia BS, Hashaikeh R (2016) Nickel oxide nanocrystals as a lithiumion battery anode: structure-performance relationship. J. Mater. Sci. 51:66246638. doi: 10.1007/s10853-016-9946-Z

[21] Piedboeuf M-LC, Leonard AF, Deschamps FL, Job N (2016) Carbon xerogels as model materials: toward a relationship between pore texture and electrochemical behavior as anodes for lithium-ion batteries. J. Mater. Sci. 51:4358-4370. doi: $10.1007 / \mathrm{s} 10853-016-9748-3$ 
[22] Moyseowicz A, Sliwak A, Gryglewicz G (2016) Influence of structural and textural parameters of carbon nanofibers on their capacitive behavior. J. Mater. Sci. 51:3431-3439. doi: 10.1007/s10853-015-9660-2

[23] Gnanaraj JS, Cohen YS, Levi MD, Aurbach D (2001) The effect of pressure on the electroanalytical response of graphite anodes and $\mathrm{LiCoO}_{2}$ cathodes for $\mathrm{Li}$-ion batteries. J. Electroanal. Chem. 516: 89-102. doi: 10.1016/S0022-0728(01)006635

[24] Striebel KA, Sierra A, Shim J, Wang CW, Sastry AM (2004) The effect of compression on natural graphite anode performance and matrix conductivity. J. Power Sources 134: 241-251. doi: 10.1016/j.jpowsour.2004.03.052

[25] Zheng H, Liu G, Song X, Ridgway O, Xun S, Battaglia VS (2010) Cathode performance as a function of inactive material and void fractions. J. Electrochem. Soc. 157: A1060-A1066. doi: 10.1149/1.3459878

[26] Fongy C, Gaillot AC, Jouanneau S, Guyomard D, Lestriez B (2010) Ionic vs electronic power limitations and analysis of the fraction of wired grains in $\mathrm{LiFePO}_{4}$ composite electrodes. J. Electrochem. Soc. 157: A885-A891. doi: $10.1149 / 1.3432559$

[27] Fongy C, Jouanneau S, Guyomard D, Badot JC, Lestriez B (2010) Electronic and ionic wirings versus the insertion reaction contributions to the polarization in $\mathrm{LiFePO}_{4}$ composite electrodes. J. Electrochem. Soc. 157: A1347-A1353. doi: $10.1149 / 1.3497353$

[28] Van Bommel A, Divigalpitiya R (2012) Effect of calendaring $\mathrm{LiFePO}_{4}$ electrodes. J. Electrochem. Soc. 159: A1791-A1795. doi: 10.1149/2.029211jes 
[29] Zheng H, Tan L, Liu G, Song X, Battaglia VS (2012) Calendering effects on the physical and electrochemical properties of $\mathrm{Li}\left[\mathrm{Ni}_{1 / 3} \mathrm{Mn}_{1 / 3} \mathrm{Co}_{1 / 3}\right] \mathrm{O}_{2}$ cathode. $\mathrm{J}$.

Power Sources 208: 52-57. doi: 10.1016/j.jpowsour.2012.02.001

[30] Park YS, Oh ES, Lee SM (2014) Effect of polymeric binder type on the thermal stability and tolerance to roll-pressing of spherical natural graphite anodes for Liion batteries. J. Power Sources 248: 1191-1196. doi:

10.1016/j.jpowsour.2013.10.076

[31] Cocco AP, Nelson GJ, Harris WM, Nakajo A, Myles TD, Kiss AM, Lombardo JJ, Chiu WKS (2013) Three-dimensional microstructural imaging methods for energy materials. Phys. Chem. Chem. Phys. 15: 16377-16407. doi:

\subsection{9/C3CP52356J}

[32] Maire E, Withers OJ (2014) Quantitative X-ray tomography. Int. Mater. Rev 59: 1-43. Doi: 10.1179/1743280413Y.0000000023

[33] Stampanoni M, Mokso R, Marone F, Vila-Comamala J, Gorelick S, Trtik P, Jefimovs K , David C (2010) Phase-contrast tomography at the nanoscale using hard X-rays. Phys. Rev. B 81: 140105. doi: 10.1103/PhysRevB.81.140105

[34] Wilson JR, Cronin JS, Barnett SA, Harris SJ (2011) Measurement of threedimensional microstructure in a $\mathrm{LiCoO}_{2}$ positive electrode. J. Power Sources 196: 3443-3447. doi: 10.1016/j.jpowsour.2010.04.066

[35] Hutzenlaub T, Thiele S, Zengerle R, Ziegler C (2011) Three-dimensional reconstruction of a $\mathrm{LiCoO}_{2} \mathrm{Li}$-ion battery cathode. Electrochem. Solid-State Lett. 15: A33-A36. doi: 10.1149/2.002203esl 
[36] Hutzenlaub T, Asthana A, Becker J, Wheeler DR, Zengerle R, Thiele S (2013) FIB/SEM-based calculation of tortuosity in a porous $\mathrm{LiCoO}_{2}$ cathode for a $\mathrm{Li}$-ion battery. Electrochem. Comm. 27: 77-80. doi: 10.1016/j.elecom.2012.11.006

[37] Liu Z, Scott Cronin J, Chen-Wiegart YCK, Wilson JR, Yakal-Kremski KJ, Wang J, Faber KT, Barnett SA (2013) Three-dimensional morphological measurements

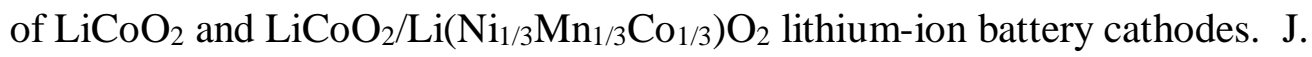
Power Sources 227: 267-274. doi: 10.1016/j.jpowsour.2012.11.043

[38] Chen-Wiegart YCK, DeMike R, Erdonmez C, Thornton K, Barnett SA, Wang J (2014) Tortuosity characterization of 3D microstructure at nano-scale for energy storage and conversion materials. J. Power Sources 249: 349-356. doi: 10.1016/j.jpowsour.2013.10.026

[39] Chen-Wiegart YCK, Liu Z, Faber KT, Barnett SA, Wang J (2013) 3D analysis of $\mathrm{LiCoO}_{2}-\mathrm{Li}\left(\mathrm{Ni}_{1 / 3} \mathrm{Mn}_{1 / 3} \mathrm{Co}_{1 / 3}\right) \mathrm{O}_{2} \mathrm{Li}$-ion battery positive electrode using $\mathrm{X}$-ray nanotomography. Electrochem. Comm. 28: 127-130. doi:

10.1016/j.elecom.2012.12.021

[40] Komini Babu S, Mohamed AI, Whitacre JF, Litster S (2015) Multiple imaging mode X-ray computed tomography for distinguishing active and inactive phases in lithium-ion battery cathodes. J. Power Sources 283: 314-319. doi: 10.1016/j.jpowsour.2015.02.086

[41] Zielke L, Hutzenlaub T, Wheeler DR, Manke I, Arlt T, Paust N, Zengerle R, Thiele S (2014) A combination of X-ray tomography and carbon binder modeling: reconstructing the three phases of $\mathrm{LiCoO}_{2} \mathrm{Li}$-ion battery cathodes. Adv. Energy Mater. 4: 1301617. doi: 10.1002/aenm.201301617 
[42] Zielke L, Hutzenlaub T, Wheeler DR, Chao CW, Manke I, Hilger A, Paust N, Zengerle R, Thiele S (2015) Three-phase multiscale modeling of a $\mathrm{LiCoO}_{2}$ cathode: combining the advantages of FIB-SEM imaging and X-ray tomography. Adv. Energy Mater. 5 doi: 10.1002/aenm.201401612

[43] Ebner M, Geldmacher F, Marone F, Stampanoni M, Wood V (2013) X-ray tomography of porous, transition metal oxide based lithium ion battery electrodes. Adv. Energy Mater. 3: 845-850. doi: 10.1002/aenm.201200932

[44] Song B, Sui T, Ying S, Li L, Lu L, Korsunsky AM (2015) Nano-structural changes in Li-ion battery cathodes during cycling revealed by FIB-SEM serial sectioning tomography. J. Mater. Chem. A 3: 18171-18179. doi:

\subsection{9/C5TA04151A}

[45] Channagiri SA, Nagpure SC, Babu SS, Noble GJ, Hart RT (2013) Porosity and phase fraction evolution with aging in lithium iron phosphate battery cathodes. J. Power Sources 243: 750-757. doi: 10.1016/j.jpowsour.2013.06.023

[46] Ender M, Joos J, Carraro T, Ivers-Tiffée E (2011) Three-dimensional reconstruction of composite cathode for lithium-ion cells. Electrochem. Comm. 13: 166-168. doi: 10.1016/j.elecom.2010.12.004

[47] Ender M, Joos J, Carraro T, Ivers-Tiffée E (2012) Quantitative characterization of $\mathrm{LiFePO}_{4}$ cathodes reconstructed by FIB/SEM tomography. J. Electrochem. Soc. 159: A972-A980. doi: 10.1149/2.033207jes

[48] Cooper SJ, Eastwood DS, Gelb J, Damblanc G, Brett DJL, Bradley RS, Withers PJ, Lee PD, Marquis AJ, Brandon NP, Shearing PR (2014) Image based 
modelling for microstructural heterogeneity in $\mathrm{LiFePO}_{4}$ electrodes for $\mathrm{Li}$-ion batteries. J. Power Sources 247: 1033-1039. doi: 10.1016/j.jpowsour.2013.04.156

[49] Jiao LA, Li X, Ren LL, Kong LY, Hong YL, Li ZW, Huang XB, Tao XF (2015) 3D structural properties study on compact $\mathrm{LiFePO}_{4}$ based on X-ray computed tomography technique. Powder Technol. 281: 1-6. doi:

10.1016/j.powtec.2015.04.063

[50] Bauer W, Nötzel D (2014) Rheological properties and stability of NMP based cathode slurries for lithium ion batteries. Ceram. Int. 40: 4591-4598. doi: 10.1016/j.ceramint.2013.08.137

[51] Imachi N, Takano Y, Fujimoto H, Kida Y, Fujitani S (2007) Layered Cathode for Improving Safety of Li-Ion Batteries. J. Electrochem. Soc. 154: A412. doi: $10.1149 / 1.2709503$

[52] Whitacre JF, Zaghib K, West WC, Ratnakumar BV (2008) Dual active material composite cathode structures for Li-ion batteries. J. Power Sources 177: 528-536. doi: 10.1016/j.jpowsour.2007.11.076

[53] Etiemble A, Besnard N, Adrien J, Tran-Van P, Gautier L, Lestriez B, Maire E (2015) Quality control tool of electrode coating for lithium-ion batteries based on X-ray radiography. J. Power Sources 298: 285-291. doi:

10.1016/j.jpowsour.2015.08.030

[54] Cloetens P, Pateyron-Salomé M, Buffiere JY, Peix G, Baruchel J, Peyrin F, Schlenker M (1997) Observation of microstructure and damage in materials by phase sensitive radiography and tomography. J. Appl. Phys. 81: 5878-5886. doi: $10.1063 / 1.364374$ 
[55] Schindelin J, Arganda-Carreras I, Frise E, Kaynig V, Longair M, Pietzsch T, Preibisch S, Rueden C, Saalfeld S, Schmid B, Tinevez JY, White DJ, Hartenstein V, Eliceiri K, Tomancak P, Cardona A (2012) Fiji: an open-source platform for biological-image analysis. Nat. Meth. 9: 676-682. doi: 10.1038/nmeth.2019.

[56] Fehrenbach J, Weiss P, Lorenzo C (2012) Variational algorithms to remove stationary noise. Application to microscopy imaging. IEEE Trans. Image Process. 21: 4420-4430. doi: 10.1109/TIP.2012.2206037

[57] Prill T, Schladitz K, Jeulin D, Faessel M, Wieser C (2013) Morphological segmentation of FIB-SEM data of highly porous media. J. Microsc. 250: 77-87. doi: $10.1111 /$ jmi. 12021

[58] Loretz M, Maire E, Baillis D (2008) Analytical modelling of the radiative properties of metallic foams: contribution of X-ray tomography. Adv. Eng. Mater. 10: 352-360. doi: 10.1002/adem.200700334

[59] Vicente J, Wyart Y, Moulin P (2013) Characterization (two-dimensional-threedimensional) of ceramic microfiltration membrane by synchrotron radiation: new and abraded membranes. J. Porous Media 16: 537-545. doi:

10.1615/JPorMedia.v16.i6.50

[60] Elmoutaouakkil A, Salvo L, Maire E, Peix G (2002) 2D and 3D characterization of metal foams using X-ray tomography. Adv. Eng. Mater. 4: 803-807. doi: 10.1002/1527-2648(20021014)4:10<803::AID-ADEM803>3.0.CO;2-D

[61] Ho BP, Leal LG (1974) Inertial migration of rigid spheres in two-dimensional unidirectional flows. J. Fluid Mech. 65: 365-400. doi:

$10.1017 /$ S0022112074001431 


\section{Table captions}

Table 1. Composition, porosity and thickness (without aluminum collector) of NMC, LFP and blended NMC/LFP cathodes.

Table 2. Morphological characteristics evaluated by FIB/SEM tomography.

Table 3. Specific surface area of the NMC particles, LFP particles and CB+PVdF phase, as as calculated from FIB/SEM tomography reconstructions.

Table 4. Specific surface area of the electrodes, as calculated from the BET specific surface areas and the weight fractions of the powders, as measured by the BET technique, as calculated from FIB/SEM tomography reconstructions.

\section{Figure captions}

Fig. 1. SEM images of (a) NMC (A) electrode, (b) NMC (B) electrode, (c) 75/25 (E) NMC/LFP electrode, (d) 50/50 NMC/LFP (G) electrode, (e) 25/75 (I) NMC/LFP electrode and (f) LFP (J) electrode cross-sections.

Fig. 2. Grey-scale X-ray attenuation image of a cross-section slice for (a-d) NMC (electrodes A-D), (e-i)) NMC/LFP (E-I) and (j-k)) LFP (J-K) electrodes.

Fig. 3. FIB/SEM Image segmentation process: grey-scale SEM image (BSE mode) of a slice of the electrode with pores segmentation outlines (red) for (a) NMC (A), (b) LFP (J), (c) as-received NMC/LFP (F) and (d) supercalendered NMC/LFP $(\mathrm{H})$ electrodes.

Fig. 4. (a-d) 3D XCT reconstructed views of the NMC particles in the electrode for various compositions and 3D FIB/SEM reconstructed views of (e-g) NMC 
(A), (h-j) as-received NMC/LFP 50/50 (F), (k-m) supercalendered NMC/LFP 50/50 (H) and (n-p) LFP (J) electrodes.

Fig. 5. Size distributions of (a) NMC particles, (b) LFP particles and (c) CB+PVdF mixture in electrodes $\mathrm{A}, \mathrm{F}, \mathrm{H}$ and $\mathrm{J}$.

Fig. 6. NMC density profiles along the thickness (XCT) of (a) NMC and (b) blended NMC/LFP electrodes. LFP density profiles along the thickness (XCT) of (c) LFP and (d) blended NMC/LFP electrodes. NMC density fraction profiles along the thickness of the $25 \%$ least and most voluminous NMC particles of (e-f) NMC and ( $g-h)$ blended NMC/LFP electrodes.

Fig. 7. NMC, LFP, CB+PVdF and pores density profiles along the thickness of a sample volume located at the surface (FIB/SEM) of (a) NMC (A), (b) asreceived NMC/LFP (F), (c) supercalendered NMC/LFP (H) and (d) LFP (J) electrodes.

Fig. 8. Schematic drawing of the typical features in (a) NMC, (b) LFP and (c) NMC/LFP composite electrodes. 
Table 1

\begin{tabular}{|c|c|c|c|c|c|c|}
\hline Ref. & $\begin{array}{c}\text { NMC/LFP } \\
\text { Compaction } \\
\end{array}$ & $\begin{array}{c}\text { Content } \\
(\mathbf{w .} \%) /(\mathbf{v} \%)^{*}\end{array}$ & $\begin{array}{l}\text { Porosity } \\
(\text { vol. \% })\end{array}$ & $\begin{array}{c}\text { Thickness } \\
\text { ( } \mu \mathrm{m})\end{array}$ & $\begin{array}{c}\text { NMC vol. density } \\
\text { (vol. \%) }\end{array}$ & $\begin{array}{c}\text { LFP vol. density } \\
\text { (vol. \%) }\end{array}$ \\
\hline & & $\begin{array}{c}N M C \\
L F P \\
P V d F \\
C B\end{array}$ & & $\begin{array}{c}\text { Micrometer } \\
X C T\end{array}$ & $\begin{array}{c}X C T \\
R S D \\
\text { Slope }\left(\mu m^{-1}\right)\end{array}$ & $\begin{array}{c}X C T \\
R S D \\
\text { Slope }\left(\mu m^{-1}\right)\end{array}$ \\
\hline $\mathbf{A}$ & $\begin{array}{c}100 / 0 \\
\text { As-received }\end{array}$ & $\begin{array}{c}92 / 54.2 \\
0 \\
5 / 7.6 \\
3 / 4.2\end{array}$ & 34 & $\begin{array}{l}69 \\
73\end{array}$ & $\begin{array}{r}54.7 \\
10.8 \\
-0.05\end{array}$ & $X$ \\
\hline B & $\begin{array}{c}100 / 0 \\
\text { As-received }\end{array}$ & $\begin{array}{c}88 / 52.2 \\
0 \\
7.5 / 11.5 \\
4.5 / 6.3\end{array}$ & 30 & $\begin{array}{l}73 \\
81\end{array}$ & $\begin{array}{r}47.7 \\
10.9 \\
-0.11\end{array}$ & $X$ \\
\hline $\mathbf{C}$ & $\begin{array}{c}100 / 0 \\
\text { As-received }\end{array}$ & $\begin{array}{c}88 / 44.7 \\
0 \\
7.5 / 9.9 \\
4.5 / 5.4\end{array}$ & 40 & $\begin{array}{l}83 \\
81\end{array}$ & $\begin{array}{c}41.8 \\
12.1 \\
-0.12\end{array}$ & $X$ \\
\hline D & $\begin{array}{c}100 / 0 \\
\text { Super } \\
\text { calendered }\end{array}$ & $\begin{array}{c}88 / 48.5 \\
0 \\
7.5 / 10.7 \\
4.5 / 5.8 \\
\end{array}$ & 35 & $\begin{array}{l}75 \\
76\end{array}$ & $\begin{array}{r}41.6 \\
11.8 \\
-0.08\end{array}$ & $X$ \\
\hline $\mathbf{E}$ & $\begin{array}{c}75 / 25 \\
\text { As-received }\end{array}$ & $\begin{array}{c}69 / 38.5 \\
23 / 16.4 \\
5 / 7.2 \\
3 / 3.9\end{array}$ & 34 & $\begin{array}{l}73 \\
77\end{array}$ & $\begin{array}{r}38.4 \\
12.0 \\
-0.11\end{array}$ & $\begin{array}{l}14.3 \\
25.2 \\
0.06\end{array}$ \\
\hline $\mathbf{F}$ & $\begin{array}{c}50 / 50 \\
\text { As-received }\end{array}$ & $\begin{array}{c}44 / 24.0 \\
44 / 30.6 \\
7.5 / 10.6 \\
4.5 / 5.8\end{array}$ & 29 & $\begin{array}{l}77 \\
78\end{array}$ & $\begin{array}{r}21.5 \\
14.0 \\
-0.05\end{array}$ & $\begin{array}{l}31.6 \\
9.5 \\
0.02\end{array}$ \\
\hline $\mathbf{G}$ & $\begin{array}{c}50 / 50 \\
\text { As-received }\end{array}$ & $\begin{array}{c}46 / 24.0 \\
46 / 30.6 \\
5 / 6.7 \\
3 / 3.7\end{array}$ & 35 & $\begin{array}{l}77 \\
77\end{array}$ & $\begin{array}{c}22.0 \\
13.8 \\
-0.08\end{array}$ & $\begin{array}{c}33.8 \\
7.7 \\
0.04\end{array}$ \\
\hline $\mathbf{H}$ & $\begin{array}{c}50 / 50 \\
\text { Super } \\
\text { calendered }\end{array}$ & $\begin{array}{c}46 / 25.5 \\
46 / 32.5 \\
5 / 7.1 \\
3 / 3.9\end{array}$ & 31 & $\begin{array}{l}71 \\
73\end{array}$ & $\begin{array}{c}24.0 \\
12.8 \\
-0.04\end{array}$ & $\begin{array}{c}34.0 \\
5.6 \\
0.01\end{array}$ \\
\hline $\mathbf{I}$ & $\begin{array}{c}25 / 75 \\
\text { As-received }\end{array}$ & $\begin{array}{c}23 / 11.4 \\
69 / 43.7 \\
5 / 6.4 \\
3 / 3.5\end{array}$ & 35 & $\begin{array}{l}83 \\
81\end{array}$ & $\begin{array}{c}9.3 \\
24.2 \\
-0.05\end{array}$ & $\begin{array}{c}47.2 \\
3.6 \\
0.00\end{array}$ \\
\hline $\mathbf{J}$ & $\begin{array}{c}\text { 0/100 } \\
\text { As-received }\end{array}$ & $\begin{array}{c}0 \\
92 / 53.9 \\
5 / 5.9 \\
3 / 3.2 \\
\end{array}$ & 37 & $\begin{array}{l}88 \\
95\end{array}$ & X & $\begin{array}{c}52.6 \\
1.7 \\
0.00\end{array}$ \\
\hline $\mathbf{K}$ & $\begin{array}{c}\text { 0/100 } \\
\text { Super } \\
\text { calendered }\end{array}$ & $\begin{array}{c}0 \\
92 / 59.8 \\
5 / 6.6 \\
3 / 3.6\end{array}$ & 30 & $\begin{array}{l}78 \\
80\end{array}$ & $\mathrm{X}$ & $\begin{array}{c}56.8 \\
0.7 \\
0.00\end{array}$ \\
\hline
\end{tabular}

*The $v \%$ takes into consideration the sample porosity 
Table 2

\begin{tabular}{|c|c|c|c|c|c|c|}
\hline Ref. & $\begin{array}{l}\text { NMC vol. } \\
\text { density (\%) }\end{array}$ & $\begin{array}{c}\text { LFP vol. } \\
\text { density } \\
(\%)\end{array}$ & $\begin{array}{c}\text { CB+PVdF vol. } \\
\text { density (\%) }\end{array}$ & $\begin{array}{c}\text { Porosity } \\
(\%)\end{array}$ & $\begin{array}{c}\text { LFP/porosity } \\
\text { ratio }\end{array}$ & $\underset{\text { ratio }}{\mathrm{LFP} / \mathrm{CB}+\mathrm{PVdF}}$ \\
\hline & $\begin{array}{c}\text { Average } \\
R S D\end{array}$ & $\begin{array}{c}\text { Average } \\
R S D\end{array}$ & $\begin{array}{c}\text { Average } \\
R S D\end{array}$ & $\begin{array}{c}\text { Average } \\
R S D\end{array}$ & $\begin{array}{c}\text { composition } \\
\text { FIB/SEM }\end{array}$ & $\begin{array}{c}\text { composition } \\
\text { FIB/SEM }\end{array}$ \\
\hline \multirow{2}{*}{$\mathbf{A}$} & 67.2 & $\mathrm{x}$ & 21.1 & 11.6 & $\mathrm{X}$ & $\mathrm{X}$ \\
\hline & 19.2 & $x$ & 39.1 & 69.8 & $X$ & $X$ \\
\hline \multirow{2}{*}{$\mathbf{F}$} & 20.4 & 36.1 & 10.0 & 33.5 & 1.1 & 1.9 \\
\hline & 33.6 & 4.2 & 13.5 & 15.3 & 1.1 & 3.6 \\
\hline \multirow{2}{*}{$\mathbf{H}$} & 15.3 & 49.6 & 10.6 & 24.5 & 1.1 & 3.0 \\
\hline & 75.4 & 24.1 & 11.6 & 6.9 & 2.0 & 4.6 \\
\hline \multirow{2}{*}{$\mathbf{J}$} & & 58.5 & 8.7 & 33.8 & 1.5 & 5.9 \\
\hline & $\mathrm{x}$ & 9.6 & 39.7 & 10.7 & 1.8 & 6.7 \\
\hline
\end{tabular}

Table 3

\begin{tabular}{|c|c|c|c|}
\hline Ref. & NMC $\left(\mathbf{m}^{\mathbf{2}} \cdot \mathbf{g}^{\mathbf{- 1}}\right)$ & LFP $\left(\mathbf{m}^{\mathbf{2}} \cdot \mathbf{g}^{\mathbf{- 1}}\right)$ & $\mathbf{C B + P V d F ~}\left(\mathbf{m}^{\mathbf{2}} \cdot \mathbf{g}^{\mathbf{- 1}}\right)$ \\
\hline Powders (BET) & 0.3 & $18.3 / 8^{*}$ & CB: 65 \\
\hline A & 0.3 & - & 3.3 \\
\hline F & 0.4 & 5.5 & 25.0 \\
\hline H & 0.8 & 6.3 & 23.6 \\
\hline J & - & 4.4 & 20.0 \\
\hline
\end{tabular}

* For LFP, the BET surface area takes into consideration the contribution of the carbon coating. Based on the LFP particles diameter, $d_{50} \cong 200 \mathrm{~nm}$ (Figure 5b), the geometrical surface area $S$ can be calculated from the well-known equation $S=6 /(d \times \rho)$, where $\rho=3.57$ $\mathrm{g} \mathrm{cm}^{-3}$.

\section{Table 4}

\begin{tabular}{|c|c|c|c|}
\hline Ref. & Theoretical $\left(\mathbf{m}^{\mathbf{2}} \cdot \mathbf{g}^{\mathbf{- 1}}\right)$ & BET $\left(\mathbf{m}^{\mathbf{2}} \cdot \mathbf{g}^{\mathbf{- 1}}\right)$ & FIB/SEM $\left(\mathbf{m}^{\mathbf{2}} \cdot \mathbf{g}^{\mathbf{- 1}}\right)$ \\
\hline $\mathbf{A}$ & 2.2 & 0.93 & 0.44 \\
\hline $\mathbf{F}$ & $11.1 / 6.6$ & 3.86 & 3.52 \\
\hline $\mathbf{H}$ & $10.5 / 5.7$ & - & 4.79 \\
\hline $\mathbf{J}$ & $18.8 / 9.3 *$ & 7.41 & 3.88 \\
\hline
\end{tabular}




\section{Figure 1}
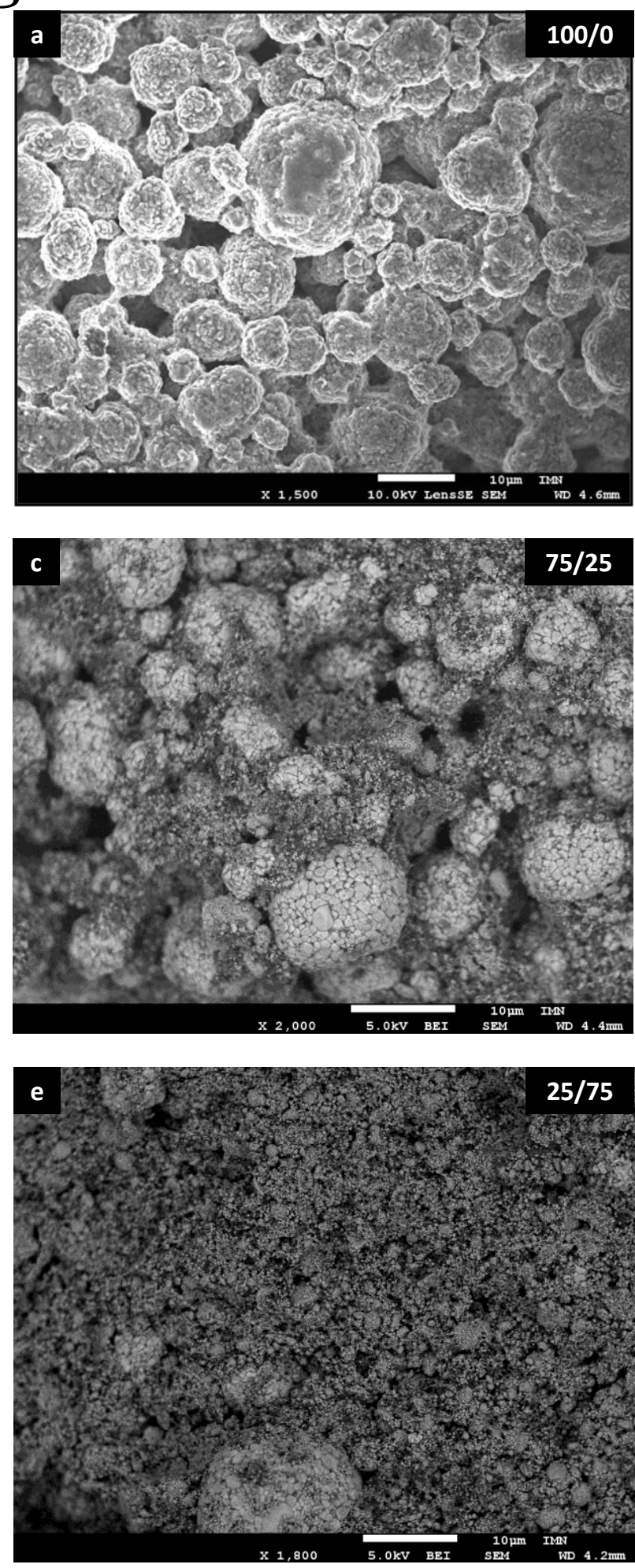
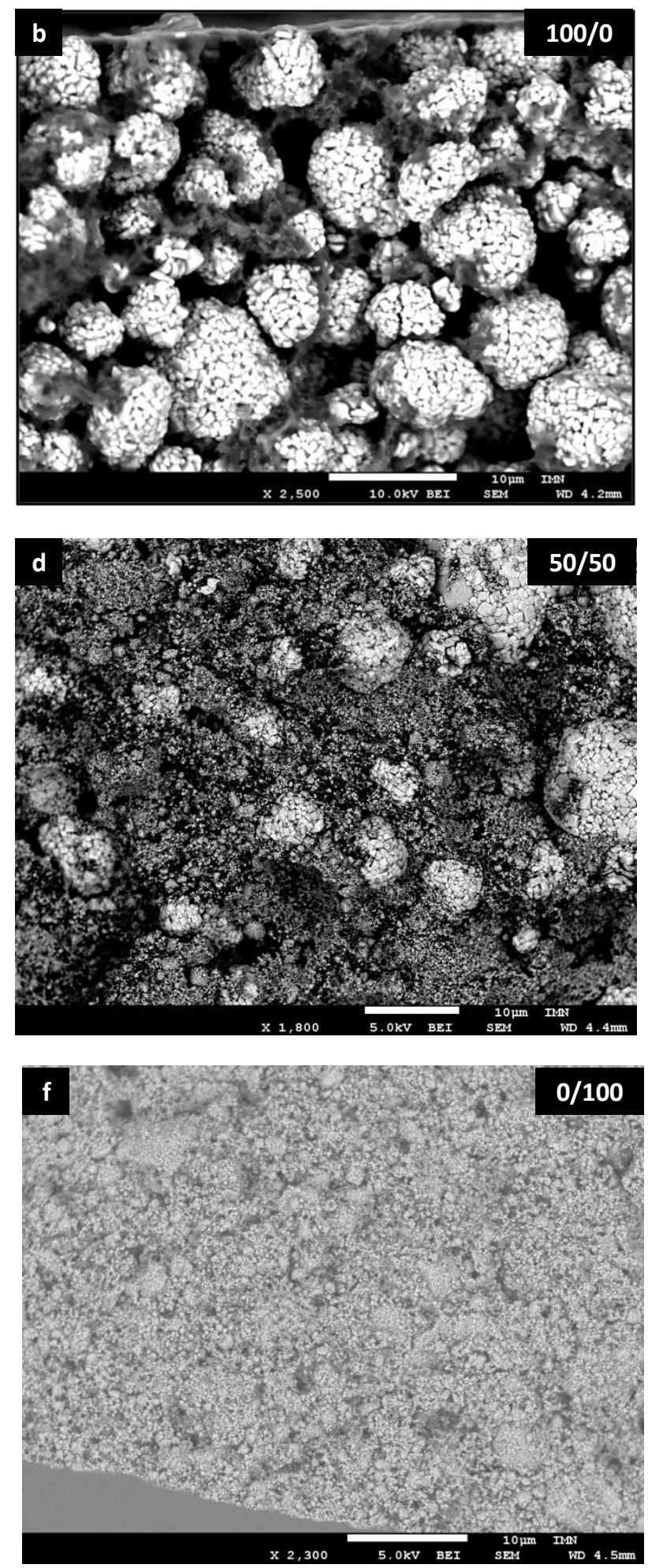


\section{Figure 2}
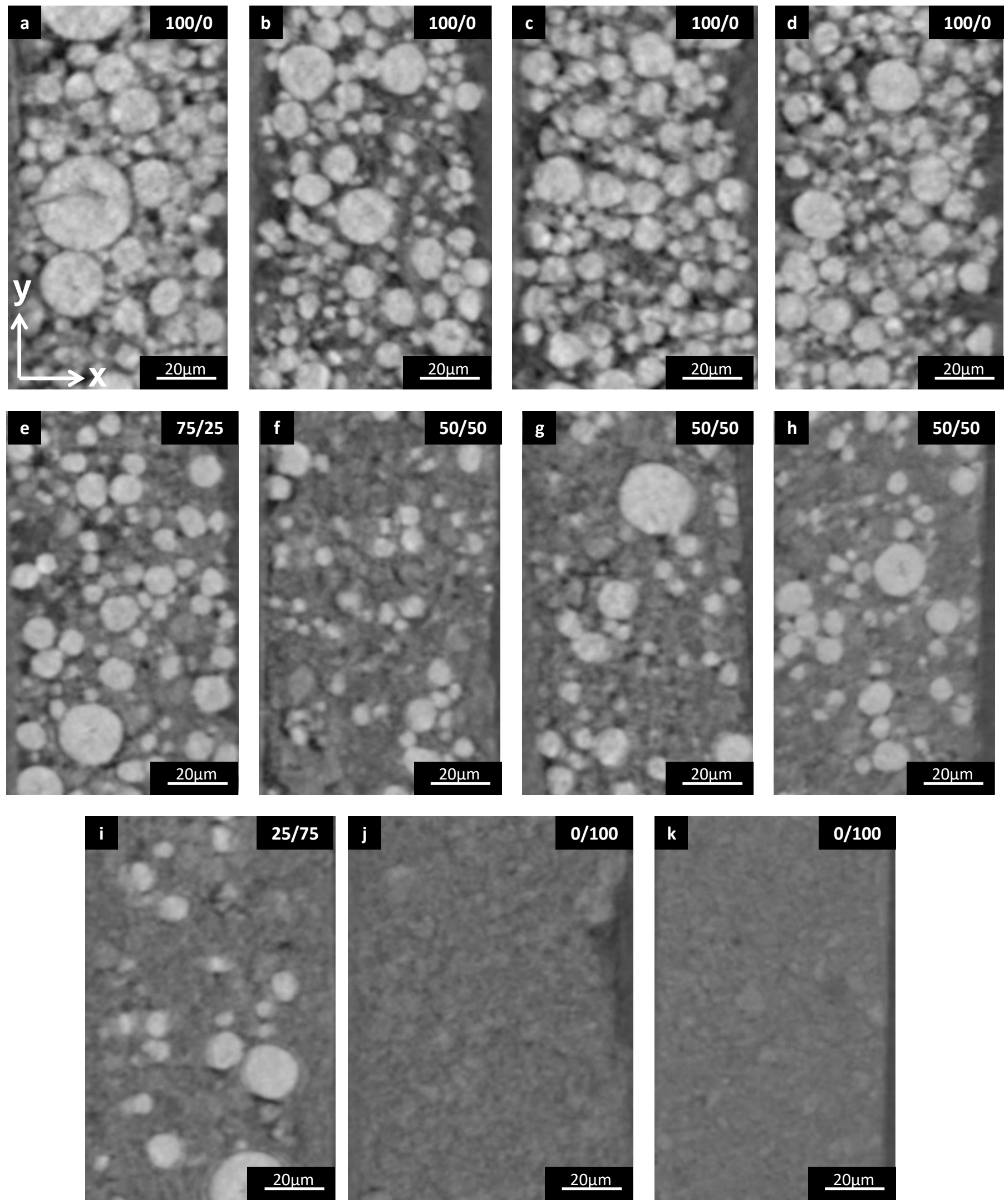

\section{0/100}

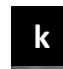

0/100 


\section{Figure 3}
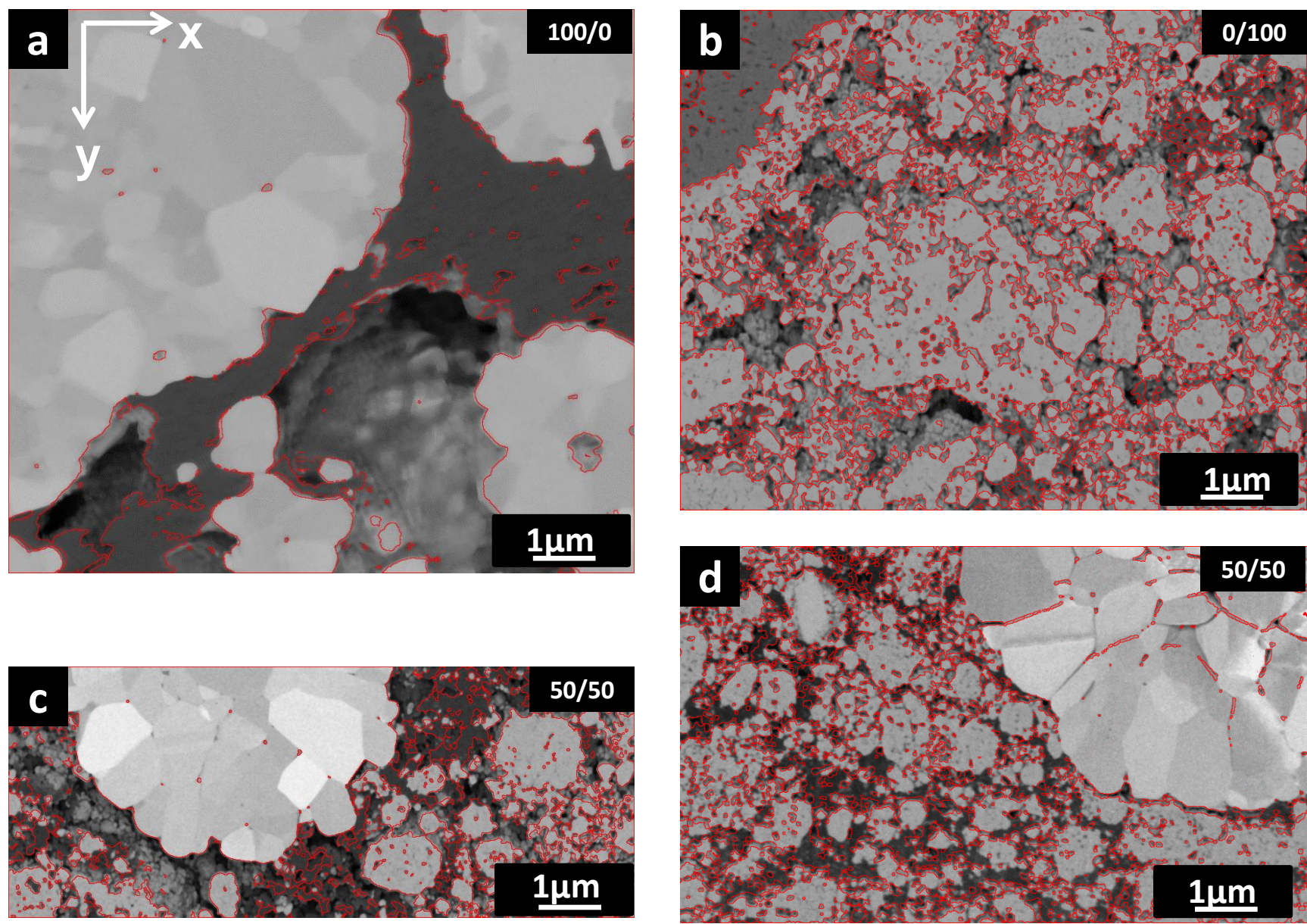


\section{Figure 4}
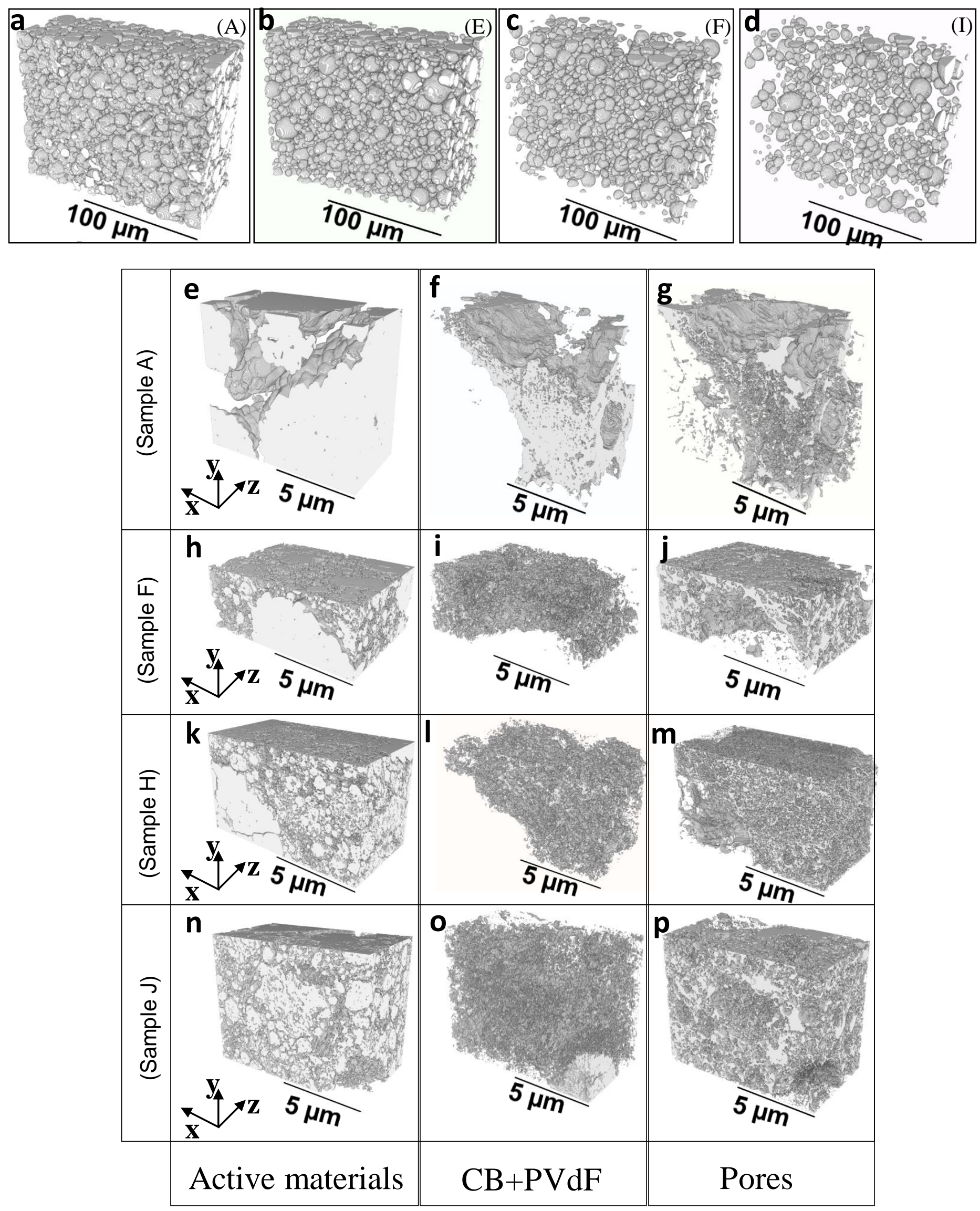


\section{Figure 5}
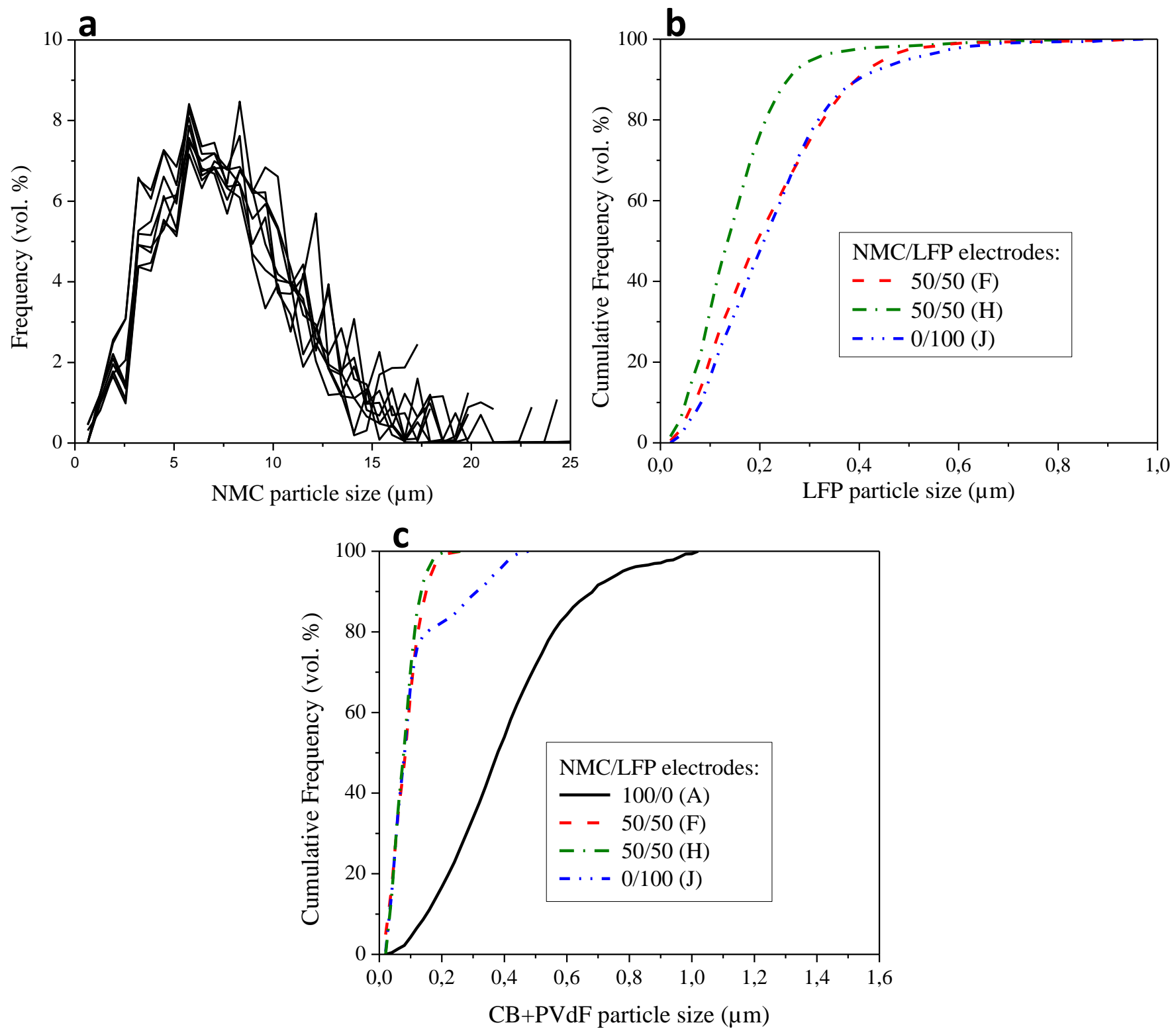

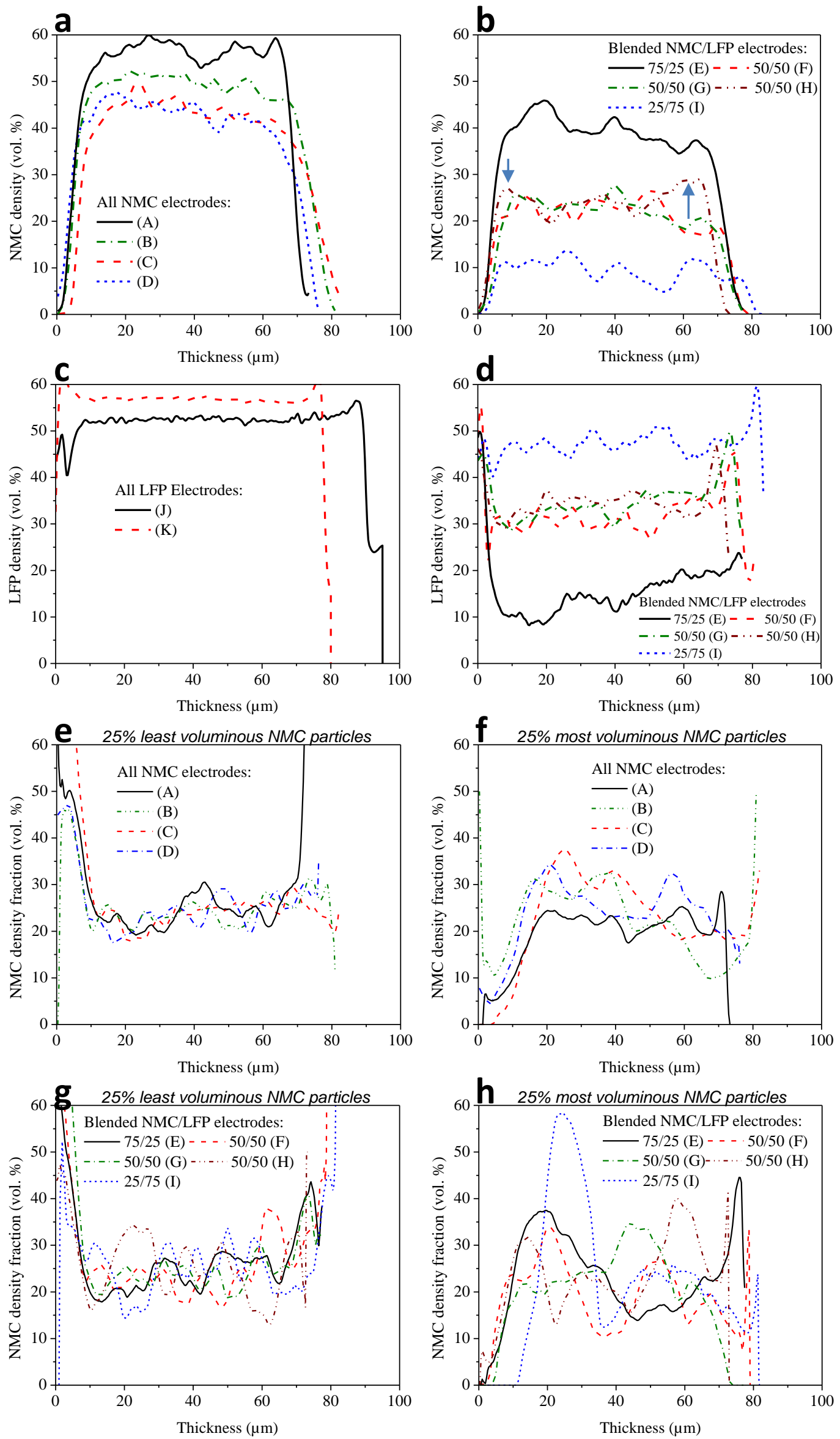

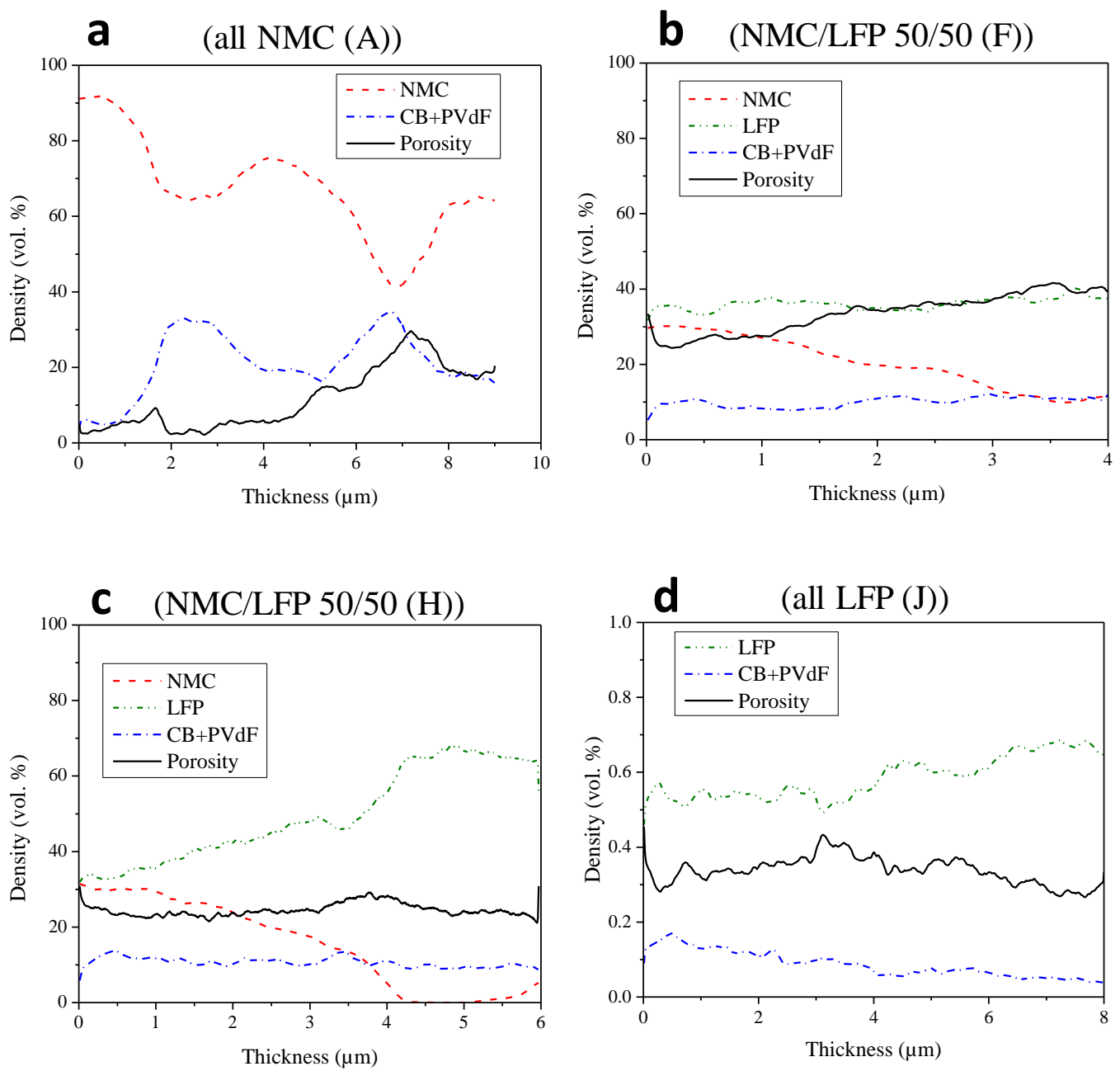


\section{Figure 8}

a

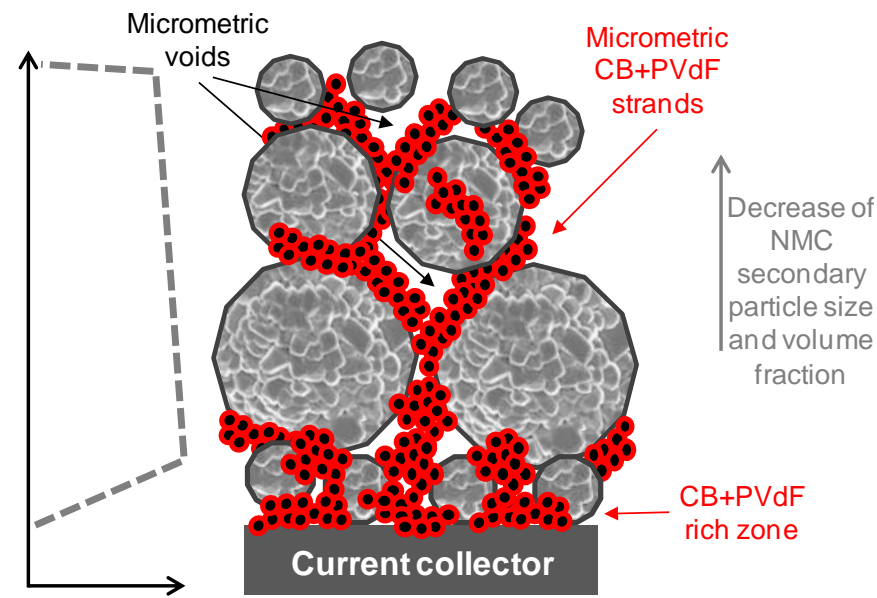

b
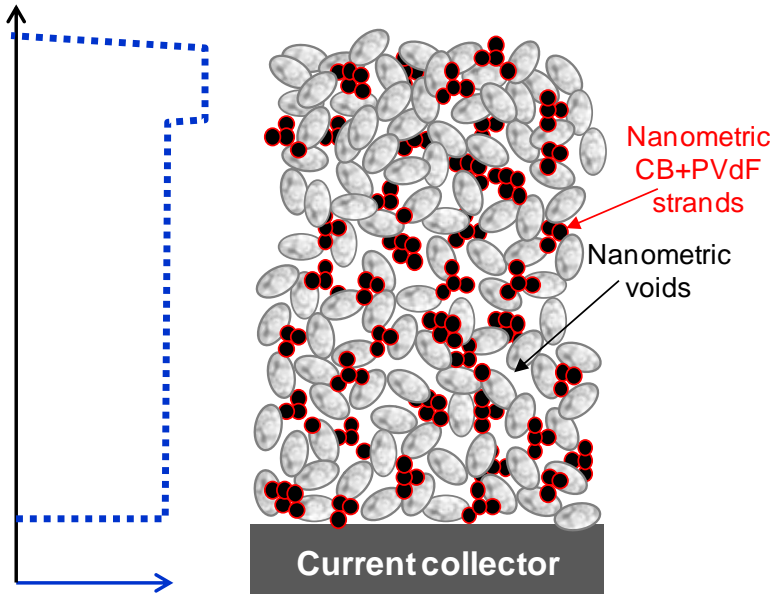

NMC density

LFP density

C

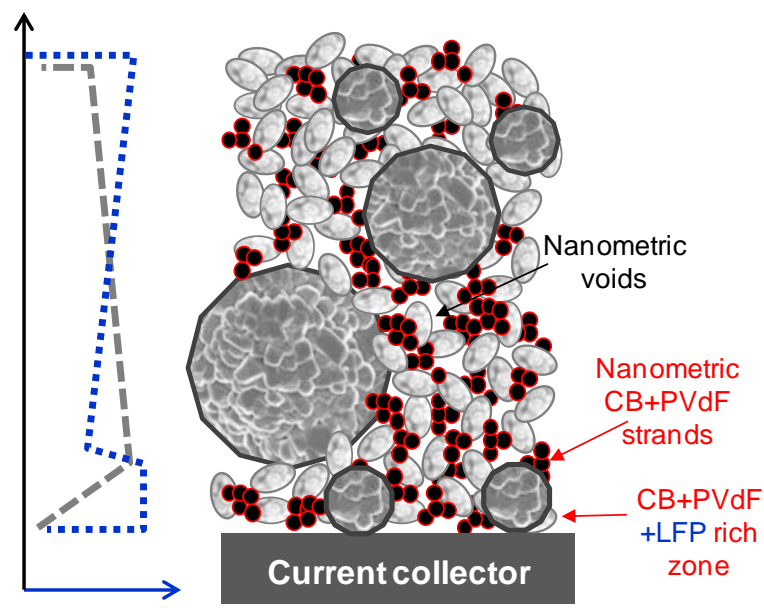

LFP density NMC density 